\title{
Impact of High-Risk Fertility Behavior on Under-five Mortality in Asia and Africa: Evidence from Demographic and Health Surveys
}

\section{Rafi Amir-ud-Din}

COMSATS University Islamabad - Lahore Campus

\section{Lubna Naz}

Karanchi University

Anila Rubi

COMSATS University Islamabad - Lahore Campus

Muhammad Usman

COMSATS University Islamabad - Lahore Campus

Umesh Ghimire ( $\nabla$ creationumesh@gmail.com )

New ERA https://orcid.org/0000-0002-4246-8379

\section{Research article}

Keywords: under-five mortality; high-risk fertility behaviors, women's age at childbirth, birth spacing and birth order, Demographic and Health Survey

Posted Date: May 22nd, 2020

DOl: https://doi.org/10.21203/rs.3.rs-29205/v1

License: (c) (1) This work is licensed under a Creative Commons Attribution 4.0 International License. Read Full License 
Impact of High-Risk Fertility Behavior on Under-five Mortality in Asia and Africa: Evidence from Demographic and Health Surveys

\section{Rafi Amir-ud-Din a ${ }^{\text {; Lubna Naz, }}{ }^{\text {; }}$ Anila Rubi ${ }^{\text {c }}$; Muhammad Usman ${ }^{\text {d }}$; Umesh Ghimire $^{\text {e* }}$}

a Assistant Professor, Department of Economics, COMSATS University Islamabad, Lahore Campus, Pakistan

${ }^{\mathrm{b}}$ Assistant Professor, Department of Economics, Karachi University, Karachi, Pakistan

${ }^{\mathrm{c}}$ Research Scholar, Department of Economics, COMSATS University Islamabad, Lahore

d Assistant Professor, Department of Management Sciences, COMSATS University

Islamabad, Lahore Campus, Pakistan

e New ERA, Kalopul, Rudramati Marga, Kathmandu, 4460o, Nepal

*Umesh Ghimire, New ERA, Kalopul, Rudramati Marga, Kathmandu, 4460o, Nepal, Email: creationumesh@gmail.com, ORCiD:https://orcid.org/oooo-ooo2-4246-8379 


\section{Abstract}

\section{Background}

High-risk fertility behaviors (HRFBs) are common in African and South Asian countries and can potentially affect child survival. This study examines the high-risk fertility behaviors concerning child mortality across the countries.

\section{Methods}

Data from a series of Demographic and Health Surveys from the year 1987 to 2016 from 24 South Asian and African countries $(\mathrm{N}=1,224,832)$ were included in this study. Four HRFB parameters - women's age $<18$ or $>=34$ years at childbirth, birth spacing $<24$ months, and child order of birth $>3$, were categorized into three exposure levels: i) exposure to any HRFBs category (exposure to any of four parameters); ii) exposure to single and multiple HRFB category (a combination of two or more parameters); and iii) the specific type of HRFB category (either single or multiple HRFB categories). Bivariate descriptive analysis and a multivariate logistic regression model were used to examine the association between under-five child mortality and various measures of HRFBs.

\section{Results}

Our pooled data analysis reported that HRFBs was associated with an increased risk of underfive child mortality in Asian and African countries. Children of women exposed to HRFBs were at increased risk of under-five mortality by $77 \%$ (Adjusted Odds Ratio (AOR) $=1.771,95 \%$ confidence interval (CI): 1.722 - 1.821). Children born within 24 months' birth interval were four times more likely to die (AOR $=4.995,95 \% \mathrm{CI}: 4.8425 .152)$ than their counterparts. However, a single high-risk category was not associated with under-five mortality, and birth order was found to be a protective factor against under-five mortality. Age of women ( $<18$ or $>=34$ years) was found to be a risk factor of Under-five child mortality in 16 countries. The association between under-five mortality risk and birth interval of less than 24 months was highly significant in all countries.

\section{Conclusion}

Women's age at childbirth, birth interval, and birth order were significantly associated with under-five mortality. Quality care for women and newborns need to be ensured through investment in the healthcare system, and by promoting health services with more focus given to 
the valuable populations through sexual and reproductive health education programs and empowering women.

Keywords: under-five mortality; high-risk fertility behaviors, women's age at childbirth, birth spacing and birth order, Demographic and Health Survey 


\section{Background}

Health is one of the crucial indicators of the socio-economic development of a country. Many lowand middle-income countries (LMICs) are facing challenges in providing affordable and quality healthcare [1]. Several socioeconomic factors, including mother's age, genetic makeup, nutritional status, alcohols, and drug consumption, are associated with child mortality [2]. Lack of skilled human resources, unavailability of advance technologies, and inadequate investment in health care significantly increase the rate of infant and maternal mortality in LMICs $[\underline{1}, \underline{3}]$.

Goal 3 of Sustainable Development Goals (SDGs) envisages to end preventable deaths of newborns and children under-five years of age and to reduce neonatal mortality to at least as low as 12 per 1000 live births and under-five mortality to at least as low as 25 per 1000 live births [4]. Evidence suggests that risky fertility behavior is the most pressing health issue in the LMICs considered as a significant cause of neonatal and under-five mortality [ $\underline{5}, \underline{6}]$. High-risk fertility behaviors (HRFBs) can be expressed in terms of too-early or too-late women's age at delivery, shorter birth interval, and a higher number of live births $[\underline{7}, \underline{8}]$. High-risk pregnancies have severe ramifications on childhood mortality [, 9-12].

Although under-five child mortality decreased by 59\% from 93 deaths per 1,000 live births in 1990 to 39 in 2018, 5.3 million children died before their fifth birthday in 2018 (Figure 1). Sub-Saharan Africa has the highest mortality rate in the world and contributes to $52 \%$ of all under-five deaths, followed by Central and Southern Asia, accounting for $29 \%$ of under-five death [13]. A study from Ethiopia indicated a higher risk of under-five mortality associated with high-risk fertility behaviors, especially amongst women aged 15 to 18 years having a high ratio of continuous pregnancies, and shorter birth spacing [14]. Bangladesh Demographic and Health Survey (DHS) report showed that $41.8 \%$ of women evinced a high risk of fertility behaviors, out of which $33 \%$ 
and $8.8 \%$ had single HRFB and possessed multiple HRFB, respectively [8]. The prevalence of teenage pregnancies in South Asian countries is high, as women are typically married at a younger age. In South Asia, the percentage of women married by their 18th birthday is $46 \%$, while those in sub-Saharan Africa are 37\% [15]. Bangladesh has the highest teenage pregnancy rate of 35\% in South Asia [16]. Around 30\% and 14\% of women in sub-Saharan are married before 18 years and 15 years, respectively [17].

Children born to a young or very old mother often pose a higher risk of child death. Social factors like age of mother, education, marital status, household wealth index, and place of residence contribute to the prevalence of high-risk pregnancies [18]. Women married at a younger age often have low education, live in poverty, lack adequate prenatal care, which could influence childbearing, and child care [19-21]. Moreover, younger women have not fully developed physiologically and gained reproductive maturity posing severe complications during pregnancy and delivery. Potentially, children born to such women are often underweight weight [22]. Unwanted pregnancies resulting from imprudent planning often create high-risk fertility among married and unmarried women [23].

Birth order of child more than three and birth spacing less than 24 months is contributing to higher rates of child mortality in South Asia $[16, \underline{24}, \underline{25}$. The birth interval between the births in South Asian countries is higher than compared to sub-Saharan Africa [26]. The birth interval of fewer than 24 months [27, 28], higher birth order [29, $\underline{30]}$ are significantly associated with higher child mortality [31-33]. Birth order of third or higher had around 30\% lower risk of Under-five death than first and second births [34]. Likewise, the shorter birth interval is a significant factor affecting child mortality under the age of five years. Optimal birth interval for child survival was found to 
be the protective factor for neonatal mortality and infant mortality. The risk of child death continued to be the lowest if the interval preceding last birth was 36 months, or more [35].

$* *$ Figure $1 * *$

Child mortality is a serious global health issue. Most of the under-five mortality occurs in developing countries in Africa and South Asia, where 2/3 of the world's poor people live. Several factors are associated with child mortality, and the importance of all are linked with high-risk fertility behaviors. Women's age at childbirth, birth spacing, and the birth order mutually affect the likelihood of the child and maternal mortality. Only a few studies have examined the impact of high-risk fertility behavior on child mortality.

Moreover, this study intended to evaluate the individual and combined influences of high-risk fertility behaviors and their association with under-five child mortality. Risky fertility behaviors need to be studied across countries to inform evidence-based policy regarding the reduction in child mortality. No study was carried out to the best of our knowledge, which has analyzed relationships at a global level. The findings of a nationally representative sample of 24 countries of South Asia and Africa would be helpful to understand if the findings across two continents contrast or not. 


\section{Methods}

\section{Data sources}

We used nationally representative data of Demographic and Health Surveys (DHSs) from 24 Africa and South Asia countries from 1987 to 2016. The DHS was implemented by the ICF international of Calverton, Maryland, USA, with the financial support from the United States Agency for International Development (USAID) after obtaining ethical approval from the ethical review board of the DHS program (http://www.dhsprogram. com) and the respective countries. The DHS collects information on critical demographic and health-related indicators such as mortality rates, fertility, family planning, maternal and child health status, and nutrition using a stratified sample of households based on cluster design with an average response rate of more than 90\%. We pooled data from all 24 countries to improve the estimation of effects and to control random sampling variation with more efficiency. A total of 1,224,832 samples of 15-49 years of women's ( $<18$ y or $>=34$ years), birth spacing ( $<24$ months), and the birth order of the child $(>3)$ women who had gone through childbirth in the previous five years were included in our analysis (Table 1). Details of the sampling design and data collection procedure for each survey are available in the respective country DHS reports.

\section{Study outcomes}

The outcome indicator analyzed in this study was under-five child mortality (the probability of a child dying before reaching the age of 5 years). The under-five mortality variable was treated as dichotomous for analysis; 1 assigned for child death and 0 for alive. 


\section{Exposures}

The primary exposure variable for this study was high-risk fertility behaviors of the mother, measured by four parameters: mother's age of 18 years or less at the time of first childbirth; mother's age 34 years or more at the time of childbirth; the latest child born in less than 24 months preceding the previous birth; and birth order of latest child three or higher. For the analysis purpose, we have categorized exposures into three categories: i) exposure to any HRFB category (exposure to any of four parameters); ii) exposure to single and multiple HRFB category (a combination of two or more single parameters; and iii) the specific types of HRFB category (either single HRFB or multiple HRFB categories).

\section{Potential confounders}

Several potential confounding factors were adjusted in studying the association between HRFB and under-five child mortality. Potential confounding variables, such as breastfeeding mothers, women's occupation, mother's education, mother's empowerment, residential status, the size of a child at birth, and wealth index, were adjusted in multiple regression analysis models.

\section{Independent variables}

We included several socio-demographic variables that are theoretically and empirically linked to high-risk fertility behavior and child mortality. Maternal age was classified into three groups: small age (16-19 years), middle-aged (20-35 years) and older age (36-49 years); birth spacing was classified into two groups: short birth interval ( $<24$ months) and long birth interval (24 or more months) and birth order (coded as 1-3 and $>3$. The outcome, exposure, and potential confounder's 
variables used in this study were coded as 0 or 1 (Table 1 ).

\section{**Table $1 * *$}

\section{Statistical analysis}

Descriptive statistics was presented as frequencies and percentages to summarize study variables. We created three models to analyze the outcome variable where each model contains different HRFB predictors (any high-risk code 1 and 0 if no risk; single high-risk code 1 and 0 if no risk; multiple high-risk code 1 and 0 if no risk). Multivariate logistic regression analysis was computed to explore the association between under-five child mortality and women's age, birth interval, and birth order. Covariates were entered simultaneously into the multivariate regression models. For the analysis, risky fertility behavior was categorized into the following three groups (i) any HRFB category (ii) single and multiple HRFB categories (iii) the specific type of HRFB category. Single high-risk fertility behavior may be characterized by any of the following condition: (i) mother's age $<18$ years at the time of childbirth (ii) mother's age $>=34$ years at the time of delivery (ii) the latest child was born $<24$ months after the previous birth, and (iv) the most recent child order of birth $>3$. For multiple high-risk fertility behavior combinations of two or more individual conditions, are required.

We used the logit regression model for analyzing the data. A general and brief sketch of the model is expressed as follows. The general logit model takes the form:

$$
y_{t}=x_{t}^{\prime} \beta+\mu_{t}
$$

Here, $y_{t}$ is a binary response variable of the children, who die before reaching the age of $5 \mathrm{y}$, satisfying the following conditions: 
$f\left(x_{\text {age }<18}\right)= \begin{cases}1, & \text { if a child dies before } 59 \text { months when } \text { mother's age }<18 \\ 0, & \text { if a child dies before } 59 \text { months when mother's age } \geq 18\end{cases}$

$f\left(x_{\text {age } \geq 34}\right)= \begin{cases}1, & \text { if a child dies before } 59 \text { months when mother's age } \geq 34 \\ 0, & \text { if a child dies before } 59 \text { months when mother's age }<34\end{cases}$

$f\left(x_{\text {spacing }}\right)= \begin{cases}1, & \text { if a child dies before } 59 \text { months when birth interval }<24 \text { months } \\ 0, & \text { if a child dies before } 59 \text { months when birth interval } \geq 24 \text { months }\end{cases}$

$f\left(x_{\text {birth order }}\right)= \begin{cases}1, & \text { if a child dies before } 59 \text { months when birth order }>3 \\ 0, & \text { if a child dies before } 59 \text { months when birth order } 1-3\end{cases}$

$f\left(x_{H R F B}\right)= \begin{cases}1, & \text { if a child dies before } 59 \text { months when } H R F B \\ 0, & \text { if a child dies before } 59 \text { months when no HRFB }\end{cases}$

and $x_{t}$ is a vector of exogenous variables. The conditional probability $P_{r}\left(y_{t}=1 \mid x_{t}\right)$ measures the likelihood of child mortality before reaching the age of 5 years due to high-risk fertility behavior. The $\mu_{t}$ is the error for $t^{t h}$ observations and the coefficient $\beta$ measures the change in the probability of child death before reaching the age of 5 years because of high-risk fertility behavior as a result of a unit change in the $x_{t}$.

$$
P_{r}\left(y_{t}=1 \mid x_{t}\right)=\frac{e^{x_{t}^{\prime}}}{1+e^{x_{t}^{\prime}}}
$$

The estimator $\tilde{\beta}$ can be estimated by maximizing the following log-likelihood function $\mathcal{L}(\beta)$.

$$
\begin{gathered}
\widetilde{\beta}=\underset{\beta}{\arg \max }[\ln \mathcal{L}(\beta)] \\
\widetilde{\beta}=\underset{\beta}{\arg \max }\left[\sum_{t}\left(y_{t} \ln \left(\frac{e^{x_{t}}}{1+e^{x_{t}}}\right)+\left(1-y_{t}\right) \ln \left(\frac{e^{x_{t}}}{1+e^{x_{t}}}\right)\right)\right]
\end{gathered}
$$


The three measures of HRFB were presented in forest plots to explain weighted estimates (risk of under-five child mortality and odds), and 95\% confidence interval. After controlling potential confounders, bivariate descriptive analysis and multivariate logistic regression analysis was conducted in Stata 14.1 using child mortality as the dependent variable and HRFB as the independent variable.

\section{Eligibility criteria}

All the observations, available in various rounds of DHSs were included. The women within 1549 years' age group, who had gone through childbirth in the previous five years, were included in our analysis. 


\section{Results}

\section{Descriptive statistics}

The overall child mortality in 24 countries was 80 per 1000 live births. The lowest child mortality was in Egypt (45/1000 lives), and the highest was in Niger (130/1000 lives). Approximately $8 \%$ of women gave birth at the age of 18 years or less, while $16 \%$ gave birth at age 34 years or above. Rwanda $(1.3 \%)$ had the least percentage of women who gave birth $\leq 18$ years, and the highest was in Bangladesh (17\%). Indian (5.7\%) and Rwanda (23\%) had the highest and lowest proportion of women aged 34 years or above who gave birth. Over one-fifth of women gave birth $\leq 18$ years or $\geq 34$ years of age. The percentage of women who gave birth either at the age of 18 years or younger or 34 years or older was lower in India (12\%) and higher in Guinea (26\%). The $10 \%$ of children were born when the birth interval was less than 24 months. Percentages of children born within 24 months' birth interval was low in Zimbabwe (5.2\%), and high in Pakistan (21\%). Over $42 \%$ of the children in our sample had the birth order of more than three. The lowest percentage of such children was in India (25\%), and the highest was in Niger (56\%) (Table 2).

\section{**Table $2 * *$}

After adjusting for covariates, high-risk fertility behaviors increased the risk of under-five child mortality by $77.1 \%(\mathrm{AOR}=1.771,95 \% \mathrm{CI}: 1.722-1.821)$. The children who were breastfed were $94.8 \%$ less likely to die than children who were never breastfed $(\mathrm{AOR}=0.0522,95 \% \mathrm{CI}$ : $0.0502-0.0544)$. The children of working women were $11.4 \%$ (95\% CI: $1.080-1.149$ ), more likely to die than the children of not working. Children of empowered mothers and from urban were $5.6 \%(\mathrm{AOR}=0.944,95 \% \mathrm{CI}: 0.917-0.970)$ and $9.5 \%(\mathrm{AOR}=0.905,95 \% \mathrm{CI}: 0.870$ - 
0.942), respectively, less likely to die relative to the mothers who were not empowered and from rural areas. A significant relationship was observed between the mothers with primary level education and the likelihood of child mortality ( $\mathrm{AOR}=0.958,95 \% \mathrm{CI}$ : $0.927-0.990)$. In comparison to the children whose mothers were uneducated, children of mothers who received secondary $(\mathrm{AOR}=0.768,95 \%$ CI: $0.734-0.804)$ and higher education $(\mathrm{AOR}=0.531,95 \% \mathrm{CI}$ : $0.473-0.595)$ were at less risk of under-five mortality. In comparison to the small size child at birth, average and large size children at birth were less likely of becoming a victim of under-five mortality. Compared to the children whose mothers were very poor, under-five children from the middle-class and rich mothers were less likely to die. The association between high-risk fertility behavior and under-five child mortality was highly significant at $\mathrm{p}<0.001$. Compared to Bangladesh, the highest risk of under-five mortality was found in Nigeria (AOR $=3.845,95 \%$ CI: $3.321-4.452)$, and the lowest was in Egypt (AOR $=0.532,95 \%$ CI: $0.466-0.607)$. As compared to 998 , the risk of under-five mortality was 3.1 times higher in 2001, but this risk was reduced to $0.50 \%$ in 2015 . (Table 3 )

**Table $3 * *$

\section{Single high-risk category}

Table 4 shows the relationship between HRFB and under-five mortality in a single high-risk category. Children whose mother's age was 18 years or below at the time of childbirth were 48.8\% (95\% CI: 1.426-1.553) more likely to die than those children born from mothers whose age was 18 years or above. Mother's age at birth 34 years or more was not significantly related to under-5 mortality. The preceding birth interval was significantly related to under-five 
mortality. However, children who were born when the birth interval was less than 24 months were four times (95\% CI: 4.842-5.152) more likely to die than those children who were born when the preceding birth interval was 24 months or more. The children whose birth order was greater than 3 were $4.3 \%$ less likely to die than those children who had birth order 1 to 3 (AOR = 0.957, 95\% CI: 0.932-0.983). The result from this study clearly showed that the children born from breastfeeding mothers, children from urban and educated mothers, average and large size of children at birth, mothers belonging to middle richer and richest were less likely to die than the reference group. The children of working mothers were more likely to die than the children of non-working mothers. Concerning the single high-risk factor, the age of younger and older mother, birth interval, and the birth order had a significantly higher risk of under-five mortality in Nigeria relative to Bangladesh. The relationship between high-risk fertility behavior and under-five mortality was highly significant at $\mathrm{p}<0.001$.

\section{**Table $4 * *$}

\section{Multiple high-risk categories}

The most common highest multiple risk factors in Nigeria were the mother's age at childbirth $<18$ years and the birth interval of $<24$ months whereas the lowest multiple risks factor in Egypt were birth interval of $<24$ months and the birth order $>3$ (Table 5). The children whose mother's age at the childbirth was $<18$ years and the children who were born in less than 24 months preceding birth were 4.6 times (95\% CI: 4.300-5.057) more likely to die. The combination of high-risk fertility behaviors such as children born to the mother whose age was < 18 years, birth order of children $>3$, and birth interval $<24$ months was not significantly associated with under- 
five child mortality. Compared to the children born from mother with no multiple risks, children born from a mother who has combination of multiple high-risk factors - children born from mothers whose age at childbirth was $>34$ years, children born within 24 months period preceding birth, and the children's order of birth >3, were 4.5 times more likely to die (95\% CI: 4.162 4.945). Likewise, children of mothers with a combination of HRFB, age at childbirth >34 years, and the birth interval $<24$ months, and the birth order $>3$, were at increased risk of dying before their fifth birthday. Children of breastfeeding mothers, urban areas, educated mothers, the average and large size of a child at birth, the middle class and rich mother's children were less likely to die than the reference group. The risk of under-five child mortality increased significantly among mothers of younger age, older mothers, birth interval less than 24 months, and birth order more than 3 in Nigeria than compared to Bangladesh.

\section{**Table $5 * *$}

Out of 24 countries, 16 countries (Bangladesh, Benin, Cameroon, Congo Democratic Republic, Guinea, India, Kenya, Madagascar, Malawi, Mali, Mozambique, Niger, Nigeria, Uganda, Egypt, and Tanzania) showed a positive association between mother's age of $<18$ or $>34$ years at childbirth and under-five child mortality. No significant association between $<18$ or $>34$ years and child under-five mortality was observed in eight countries (Ghana, Cote d'Ivoire, Morocco, Pakistan, Rwanda, Zimbabwe, Burkina Faso, and Zambia. Age factor $<18$ or $>34$ years was found to be a risk factor for the under-five mortality (Figure 2). A positive relationship between birth interval $<24$ months, and under-five child mortality was observed in all countries. In 24 
countries, the birth interval $<24$ months was associated with higher odds of child mortality.

\section{**Figure 2: Under-five mortality risks with mother's age**}

Out of 24 countries, a positive association between birth order $>3$ and child mortality was found in three countries (India, Madagascar, and Pakistan), and the negative association was observed in seven countries (Malawi, Mali, Mozambique, Rwanda, Tanzania, Uganda, and Zambia) (Figure 1). We did not find an association between birth order $>3$ and child mortality in 14 countries (Bangladesh, Benin, Burkina Faso, Cameroon, Congo Democratic Republic, Cote d'Ivoire, Ghana, Guinea, Kenya, Morocco, Niger, Nigeria, Egypt, and Zimbabwe) (Figure 4).

\section{**Figure 3: Under-five mortality risks with birth interval**}

\section{**Figure 4: Under-five mortality risks with birth order**}

\section{Discussion}

This study aimed to investigate factors associated with child mortality concerning HRFB using national representative samples from 24 countries. The descriptive analysis found that the lowest under-5 child mortality was in Egypt, and the highest under-5 child mortality was in Niger. In multivariate analyses, we found that among the children with their mother's age $<18 \mathrm{y}, 48.8 \%$ were more likely to die than those children with their mother's age $>=18$ years. These findings are consistent with some previous studies showing high mortality among children born from mothers (less than 18 years) [12, 36-39]. Another study shows that the mothers aged (13-19 years) have a high risk of neonatal mortality as compared to mothers of 20-34 years old [40]. The child mortality risk is higher among 40 years older women than compared to 35 to 39 years old 
women [41]. According to Bangladesh DHS, there is less risk of child mortality for children of adult mothers than children of teenage mothers [42].

The high risk of under-five mortality is associated with low maternal age $<18$ years. Young mothers are not fully matured physically and deprived of nutritional and biological advantages, which directly affect fetal development [43]. Later, the children born from younger mothers are associated with adverse birth outcomes, such as low birth weight, childhood stunting, and other adverse neonatal and infant health problems including childhood mortality [44-46]. In our study, the mother's age at childbirth $>=34$ years was not significantly related to under-5 mortality.

However, the likelihood of death was $2.8 \%$ less among children born from mothers aged $>=34$ years than compared to children born from mothers age 34 years or older. The fact that older mothers have a higher risk of maternal anxiety, hormonal disorder, and low uteroplacental blood flow increases the risk of congenital and chromosomal abnormalities, which further cause complications to the child $[\underline{47}, \underline{48}]$.

The birth interval of fewer than 24 months preceding birth appeared to be a more important cause of under-five death in our study. Children born before 24 months' birth interval were four times more likely to die than whose birth interval was 24 months or more preceding birth. Previous studies found a similar association between birth interval and child mortality $[\underline{12}, \underline{27}$, $\underline{28}, \underline{49-51]}$.

Shorter the birth interval higher will be the adverse effects on the mother's physiological wellbeing. Ample time is needed for the muscles of reproductive organs to gain strength and recover from depleted nutrition. Moreover, the chances of transmission of the disease increase significantly due to the short intervals [39]. Longer birth interval helps poorer families to recover 
from the economic losses and enables them to care new-borns [35]. A study showed that spacing of 2 to 5 years between births helps reduce child mortality [52]. The risk of neonatal mortality is increased by the short birth spacing of fewer than 33 months than the long birth spacing of more than 33 months [40].

In sub-Saharan Africa, shorter birth spacing is regarded as a major risk factor of child and maternal mortality. In contrast, the mortality rate is low when the birth interval is 42 to 53 months [39]. The short inter-pregnancy interval is associated with increased risk of premature membrane rupture, rupture of the uterus when women try vaginal delivery after caesarean, antepartum haemorrhage, anaemia, placental abruption which ultimately increases the risk of fetus mortality $[53, \underline{54}$. Depression of the mother due to previous neonatal death may increase the risk of subsequent mortality of neonates [31].

Children of the birth order of more than three were $4.3 \%$ less likely to die than those children having birth order one through three. While some studies have reported that low birth order has little effect on child mortality [55, 56], many studies from Asian and African countries strongly supported the association between low birth order and child mortality [49, $\underline{57-60]}$.

Some studies have shown that the risk of under-five mortality increases with the increase birth order of two $[40, \underline{61-63]}$ and four or more $[29, \underline{51}, \underline{64}$. A multi-country analysis also showed that higher birth order was negatively associated with the risk of under-five and under-two mortality. Moreover, children of the third or higher birth order had around 30\% lesser risk of child death than first and second births [34]. However, the researcher has found inconsistent findings between birth order and child survival [61].

Due to repeated births, chances are higher that mothers have septic abortions and premature 
rupture of fetal membranes or uterine bleeding affecting reproductive organs. Psychologically, a multiparous woman would have less time and energy to take care of all children, and chances of child neglect can lead to child mortality. Additionally, mother belonging to lower socioeconomic status, and low education status tend to have many children and live in less favourable lifestyle [65].

Our study outcome showed that children of working women were $11.4 \%$ more likely to die than the children of not working women. Working women have less time to look after their children due to their professional demands [66]. Moreover, they also remain under-stress because of tiresome professional and personal duties [67], leading to the risk of child mortality.

This study has some limitations. Different geographic regimes have different social, cultural, and economic dynamics. Various health vulnerabilities and genetic makeup of the participants from different countries could be a source of bias. Since exposure variables were based on interviews and self-reported accounts leading to recall bias. To avoid such biases, samples in this study were restricted to women living with their last child born in 5 years preceding the study. Being a cross-sectional study, data from DHS cannot assess causality between the predictors and underfive child mortality. Prospective investigations are required to assess the HRFB and its effect on child mortality. Lastly, the use of DHS data between 1987 and 2016 allowed us to examine the influence of various measures of HRFB across several countries of Asia and Africa.

\section{Conclusions}

The cross-country analysis of HRFB and under-five child mortality showed a positive association between under-five child mortality and various measures of HRFB, viz. women's age 
at childbirth, birth interval, and birth order of the child. Factors such as mothers breastfeeding practices, mother's occupation, education level, women's empowerment, place of residence, size of child at birth, and wealth index, increased the risk of under-five mortality. Child mortality was found to be very high in LMICs, mostly attributed to HRFBs. Awareness and health education programs through various social, print, or electronic media should be intensified to educate the rural population on sexual and reproductive health and women empowerment.

Women's age at the time of childbirth $<18 \mathrm{y}$ or $>34$ years, birth spacing $<24$ months, and birth order $>3$ were the risk factors for child mortality. These findings call for countries to indorse and end risky fertility behaviors such as health act minimum age at marriage, recommend an appropriate birth interval, promote the use of family planning methods, avoid unwanted pregnancies, and discoursing three or more pregnancies. Investment in healthcare should be increased to improve the quality of care of mothers and neonates. Community-based interventions need to strengthen by mobilizing grass-root level health workers to target women from rural areas and poverty-stricken families where the highest number of under-five mortality exists.

\section{List of abbreviations}

AOR; Adjusted Odds Ratio, CI; Confidence Interval, HRFBs; High-risk fertility behaviors, LMICs; low- and middle-income countries, DHS; Demographic and Health Survey, SDGs; Sustainable Development Goals, UNIGME; United Nations Inter-Agency Group for Child Mortality Estimation, USAID; United States Agency for International Development 


\section{DECLARATIONS}

Ethics approval and consent to participant

All countries analyzed in this paper granted ethical permission from the ethical review board of ICF and DHS program requested to conduct the survey after obtaining ethical approval from the concerned ethical review board of respective countries.

\section{Consent for publication}

Prior consent was taken from the Measure DHS program for the use and publication of this manuscript

\section{Availability of data and materials}

The data supporting this manuscript are available upon request from the DHS program website at https://dhsprogram.com/data/

\section{Competing interests}

The authors declare no competing interest regarding the publication of this paper.

\section{Funding}

None

\section{Author's contributions}

RAD and AR have conceived the research idea of this paper. RAD and $\mathrm{LN}$ have analyzed the data and estimated the model. AR, UG, and MU have written the introduction, discussion, and results. RAD and $\mathrm{LN}$ have written methods. UG, RAD, LN have critically evaluated the paper. All authors have agreed on the final version of the manuscript.

\section{Acknowledgements}

We would like to acknowledge Measure DHS for granting access to datasets for this study. 


\section{References}

1. Erdoğan E, Ener M, Arıca F. The strategic role of infant mortality in the process of economic growth: an application for high income OECD countries. Procedia-Social and Behavioral Sciences. 2013;99:19-25.

2. Corman H, Grossman M. Determinants of neonatal mortality rates in the US: A reduced form model. Journal of Health Economics. 1985;4(3):213-36.

3. Amiri A, Gerdtham U-G. Impact of maternal and child health on economic growth: New evidence based granger causality and DEA analysis. Newborn and Child Health, Study

Commissioned by the Partnership for Maternal, Lund University, Sweden. 2013.

4. SDG3.2. World Health Organization (WHO). United Nations sustainable development summit: Sustainable development goals 2018 [Available from:

http://www.who.int/topics/sustainable-development-goals/targets/en/.

5. Finlay JE, Norton MK. Adolescent Fertility and Child Health: The Interaction of Maternal Age, Parity and Birth Intervals in Determining Child Health Outcomes. International Journal of Child Health and Nutrition. 2017;6(1):16-33.

6. Gurmu E, Tariku D. Correlates of High Risk Fertility Behaviour in Ethiopia: A Multilevel Analysis of the 2011 Ethiopian Demographic and Health Survey Data Journal of Health, Medicine and Nursing. 2017;Vol.39, 2017

7. Rahman M, Haque SE, Zahan S, Islam J, Rahman M, Asaduzzaman M, et al. Maternal high-risk fertility behavior and association with chronic undernutrition among children under age 5 y in India, Bangladesh, and Nepal: Do poor children have a higher risk? Nutrition. 2018;49:3240 .

8. Rahman M, Islam MJ, Haque SE, Saw YM, Haque MN, Duc NHC, et al. Association between high-risk fertility behaviours and the likelihood of chronic undernutrition and anaemia among married Bangladeshi women of reproductive age. Public Health Nutrition. 2017;20(2):305-14.

9. Raj A, Saggurti N, Winter M, Labonte A, Decker MR, Balaiah D, et al. The effect of maternal child marriage on morbidity and mortality of children under 5 in India: cross sectional study of a nationally representative sample. BMJ. 2010;340:b4258.

10. Santhya K. Early marriage and sexual and reproductive health vulnerabilities of young women: a synthesis of recent evidence from developing countries. Current opinion in obstetrics and gynecology. 2011;23(5):334-9.

11. Raj A, Boehmer U. Girl child marriage and its association with national rates of HIV, maternal health, and infant mortality across 97 countries. Violence against women. 2013;19(4):536-51.

12. Raj A, McDougal L, Rusch ML. Effects of young maternal age and short interpregnancy interval on infant mortality in South Asia. Int J Gynaecol Obstet. 2014;124(1):86-7.

13. SDG. World Health Organization (WHO). Levels \& Trends in Child Mortality:

Sustainable development goals. 2018 [Available from: http://childmortality.org/files_v22/download/UN\%20IGME\%20Child\%20Mortality\%20Report \%202018.pdf.

14. Mekonnen Y, Ayalew T, Dejene A. High-risk birth, fertility intention, and unmet need in Addis Ababa. The Ethiopian Journal of Health Development (EJHD). 2017;12(2).

15. Loaiza E, Wong S. Marrying too young: end child marriage. New York: United Nations Population Fund; 2012. 
16. IIPS. International Institute for Population Sciences and Macro International. National Family Health Survey (NFHS-3), 2005-06: India. Mumbai: IIPS; 2007. 2007.

17. Okonofua F. Prevention of child marriage and teenage pregnancy in Africa: need for more research and innovation Il faut encore plus de recherche et d'innovation dans la prévention de la grossesse chez les enfants et les adolescentes dans les mariages africains. African Journal of Reproductive Health. 2013;17(4):9-13.

18. Maxwell L, Nandi A, Benedetti A, Devries K, Wagman J, García-Moreno C. Intimate partner violence and pregnancy spacing: results from a meta-analysis of individual participant time-to-event data from 29 low-and-middle-income countries. BMJ Global Health.

2018;3(1):e000304.

19. UNICEF. Early marriage a harmful traditional practice a statistical exploration 2005. New York: United Nations Children's Fund; 2005.

20. Santhya KG, Ram U, Acharya R, Jejeebhoy SJ, Ram F, Singh A. Associations between early marriage and young women's marital and reproductive health outcomes: evidence from India. International Perspectives on Sexual and Reproductive Health. 2010:132-9.

21. UNICEF. Ending child marriage: progress and prospects. New York: United Nations Children's Fund 2014.

22. Ahmed F. Unmarried mothers as a high-risk group for adverse pregnancy outcomes. Journal of community health. 1990;15(1):35-44.

23. Nanda S. Correlates of high-risk fertility behaviour of women and their pregnancy wastage: evidences from Orissa. Man in India. 2009;89(3):353-9.

24. Ministry of Health and Population (MOHP)/Nepal, New ERA/Nepal, ICF International Inc:. Nepal Demographic and Health Survey 2011. Calverton, Maryland: Ministry of Health and Population, New ERA, and ICF International; 2012.

25. NIPORT. NIPORT, Mitra and Associates, and Macro International. Bangladesh Demographic and Health Survey 2011. Dhaka, Bangladesh and Calverton, Maryland, USA: National Institute of Population Research and Training, Mitra and Associates, and Macro International; 2013. 2013.

26. Rutstein SO. Trends in birth spacing. Calverton, Maryland, USA: ICF Macro; 2011.

27. Ezeh OK, Agho KE, Dibley MJ, Hall J, Page AN. Determinants of neonatal mortality in Nigeria: evidence from the 2008 demographic and health survey. BMC Public Health. 2014;14:521.

28. Habimana-Kabano I, Broekhuis A, Hooimeijer P. The Effect of Pregnancy Spacing on Fetal Survival and Neonatal Mortality in Rwanda: A Heckman Selection Analysis. J Biosoc Sci. 2016;48(3):358-73.

29. Deb AK, Dutta S, Hnichho C, Vanlalpeki M, Phosa HT, Rakhu K, et al. A case control study investigating factors associated with high infant death in Saiha district of Mizoram, India bordering Myanmar. BMC Pediatr. 2017;17(1):23.

30. Maniruzzaman M, Suri HS, Kumar N, Abedin MM, Rahman MJ, El-Baz A, et al. Risk factors of neonatal mortality and child mortality in Bangladesh. J Glob Health. 2018;8(1):010417.

31. Stephansson O, Dickman PW, Cnattingius S. The influence of interpregnancy interval on the subsequent risk of stillbirth and early neonatal death. Obstetrics \& gynecology.

2003;102(1):101-8. 
32. Marchant T, Schellenberg JA, Nathan R, Abdulla S, Mukasa O, Mshinda H, et al. Anaemia in pregnancy and infant mortality in Tanzania. Tropical medicine \& international health. 2004;9(2):262-6.

33. DaVanzo J, Hale L, Razzaque A, Rahman M. Effects of interpregnancy interval and outcome of the preceding pregnancy on pregnancy outcomes in Matlab, Bangladesh. BJOG: An International Journal of Obstetrics \& Gynaecology. 2007;114(9):1079-87.

34. Uddin M. Child Mortality in a Developing Country: A Statistical Analysis. Journal of Applied Quantitative Methods. 2009;4(3):270-83.

35. Rutstein SO. Effects of preceding birth intervals on neonatal, infant and under-five years mortality and nutritional status in developing countries: evidence from the demographic and health surveys. International Journal of Gynecology \& Obstetrics. 2005;89:S7-S24.

36. Alam N. Teenage motherhood and infant mortality in Bangladesh: maternal agedependent effect of parity one. Journal of Biosocial Science. 2000;32(2):229-36.

37. Perin J, Walker N. Potential confounding in the association between short birth intervals and increased neonatal, infant, and child mortality. Glob Health Action. 2015;8:29724.

38. Wilson N. Child mortality risk and fertility: evidence from prevention of mother-to-child transmission of HIV. Journal of Development Economics. 2015;116:74-88.

39. Kravdal O. New evidence about effects of reproductive variables on child mortality in sub-Saharan Africa. Popul Stud (Camb). 2018;72(2):139-56.

40. Selemani M, Mwanyangala MA, Mrema S, Shamte A, Kajungu D, Mkopi A, et al. The effect of mother's age and other related factors on neonatal survival associated with first and second birth in rural, Tanzania: evidence from Ifakara health and demographic surveillance system in rural Tanzania. BMC Pregnancy Childbirth. 2014;14:240.

41. Morris JM, Totterdell J, Bin YS, Ford JB, Roberts CL. Contribution of maternal age, medical and obstetric history to maternal and perinatal morbidity/mortality for women aged 35 or older. Australian and New Zealand Journal of Obstetrics and Gynaecology. 2018;58(1):91-7. 42. Kamal SM. What is the association between maternal age and neonatal mortality? An analysis of the 2007 Bangladesh Demographic and Health Survey. Asia Pacific Journal of Public Health. 2015;27(2):NP1106-NP17.

43. de Vienne CM, Creveuil C, Dreyfus M. Does young maternal age increase the risk of adverse obstetric, fetal and neonatal outcomes: a cohort study. European Journal of Obstetrics \& Gynecology and Reproductive Biology. 2009;147(2):151-6.

44. Ganchimeg T, Ota E, Morisaki N, Laopaiboon M, Lumbiganon P, Zhang J, et al. Pregnancy and childbirth outcomes among adolescent mothers: a World Health Organization multicountry study. BJOG: An International Journal of Obstetrics \& Gynaecology. 2014;121:408.

45. Alio AP, Mbah AK, Grunsten RA, Salihu HM. Teenage pregnancy and the influence of paternal involvement on fetal outcomes. Journal of Pediatric and Adolescent Gynecology. 2011;24(6):404-9.

46. Chen X-K, Wen SW, Fleming N, Demissie K, Rhoads GG, Walker M. Teenage pregnancy and adverse birth outcomes: a large population based retrospective cohort study. International Journal of Epidemiology. 2007;36(2):368-73.

47. Weerasekera D, Udugama SG. Pregnancy at 40 and over: a case-control study in a developing country. Journal of Obstetrics and Gynaecology. 2003;23(6):625-7. 
48. Yogev Y, Melamed N, Bardin R, Tenenbaum-Gavish K, Ben-Shitrit G, Ben-Haroush A. Pregnancy outcome at extremely advanced maternal age. American Journal of Obstetrics and Gynecology. 2010;203(6):558. e1-. e7.

49. Brown W, Ahmed S, Roche N, Sonneveldt E, Darmstadt GL. Impact of family planning programs in reducing high-risk births due to younger and older maternal age, short birth intervals, and high parity. Semin Perinatol. 2015;39(5):338-44.

50. Hossain MM, Mani KK, Islam MR. Prevalence and determinants of the gender differentials risk factors of child deaths in Bangladesh: evidence from the Bangladesh demographic and health survey, 2011. PLoS Negl Trop Dis. 2015;9(3):e0003616.

51. Ezeh OK. Trends and population-attributable risk estimates for predictors of early neonatal mortality in Nigeria, 2003-2013: a cross-sectional analysis. BMJ Open. 2017;7(5):e013350.

52. English R, Peer N, Honikman S, Tugendhaft A, Hofman KJ. 'First 1000 days' health interventions in low- and middle-income countries: alignment of South African policies with high-quality evidence. Glob Health Action. 2017;10(1):1340396.

53. Conde-Agudelo A, Belizán JM. Maternal morbidity and mortality associated with interpregnancy interval: cross sectional study. BMJ. 2000;321(7271):1255-9.

54. Conde-Agudelo A, Rosas-Bermúdez A, Kafury-Goeta AC. Effects of birth spacing on maternal health: a systematic review. American Journal of Obstetrics and Gynecology. 2007;196(4):297-308.

55. Ahmed Z, Kamal A, Kamal A. Statistical Analysis of Factors Affecting Child Mortality in Pakistan. J Coll Physicians Surg Pak. 2016;26(6):543-4.

56. Bado AR, Appunni SS. Decomposing Wealth-Based Inequalities in Under-Five Mortality in West Africa. Iran J Public Health. 2015;44(7):920-30.

57. Conde-Agudelo A, Rosas-Bermúdez A, Kafury-Goeta AC. Birth spacing and risk of adverse perinatal outcomes: a meta-analysis. JAMA. 2006;295(15):1809-23.

58. DaVanzo J, Hale L, Razzaque A, Rahman M. The effects of pregnancy spacing on infant and child mortality in Matlab, Bangladesh: how they vary by the type of pregnancy outcome that began the interval. Population Studies. 2008;62(2):131-54.

59. Akinyemi JO, Bamgboye EA, Ayeni O. New trends in under-five mortality determinants and their effects on child survival in Nigeria: A review of childhood mortality data from 19902008. African Population Studies. 2013;27(1).

60. Fotso JC, Cleland J, Mberu B, Mutua M, Elungata P. Birth spacing and child mortality: an analysis of prospective data from the Nairobi urban health and demographic surveillance system. Journal of biosocial science. 2013;45(6):779-98.

61. Saha UR, van Soest A. Contraceptive use, birth spacing, and child survival in Matlab, Bangladesh. Stud Fam Plann. 2013;44(1):45-66.

62. Stover J, Ross J. Changes in the distribution of high-risk births associated with changes in contraceptive prevalence. BMC Public Health. 2013;13 Suppl 3:S4.

63. Chadoka-Mutanda N, Odimegwu CO. Maternal Health-Seeking Behaviour and underFive Mortality in Zimbabwe. J Biosoc Sci. 2017;49(3):408-21.

64. Sahu D, Nair S, Singh L, Gulati BK, Pandey A. Levels, trends \& predictors of infant \& child mortality among Scheduled Tribes in rural India. Indian J Med Res. 2015;141(5):709-19.

65. Konishi S, Ng CFS, Watanabe C. U-shaped association between fertility and mortality in a community-based sample of Japanese women. J Epidemiol Community Health.

2018;72(4):337-41. 
66. Spitzmueller C, Zhang J, Thomas CL, Wang ZX, Fisher GG, Matthews RA, et al. Identifying Job Characteristics Related to Employed Women's Breastfeeding Behaviors. J Occup Health Psych. 2018;23(4):457-70.

67. Mutambudzi M, Siegrist J, Meyer JD, Li J. Association between effort-reward imbalance and self-reported diabetes mellitus in older US workers. J Psychosom Res. 2018;104:61-4. 


\section{Figure Legends}

Figure 1: Global under-five, neonatal, infant mortality rates (1990-2017)

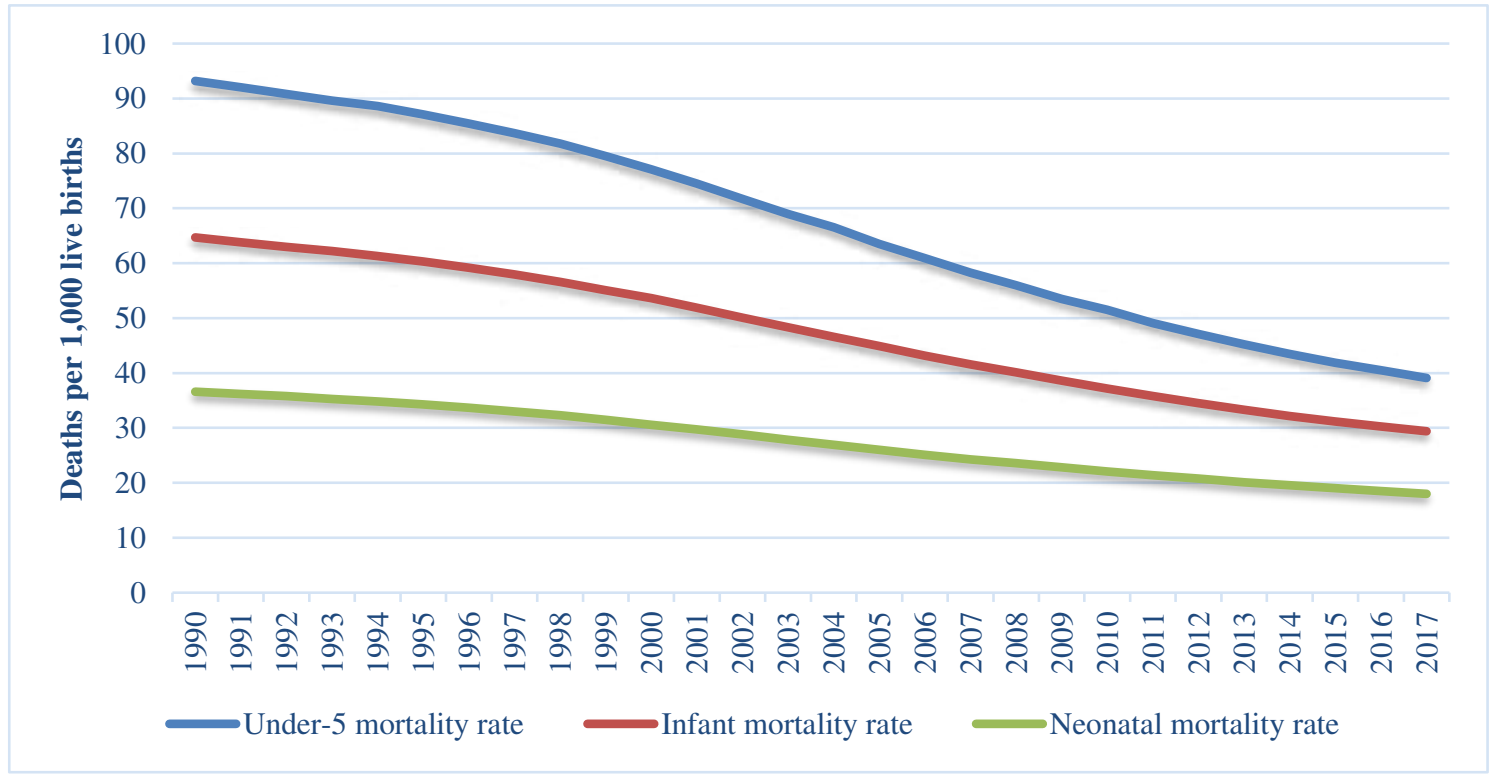

Source: United Nations Inter-Agency Group for Child Mortality Estimation (UNIGME) 2018 
Figure 2: Under-five mortality risks with mother's age

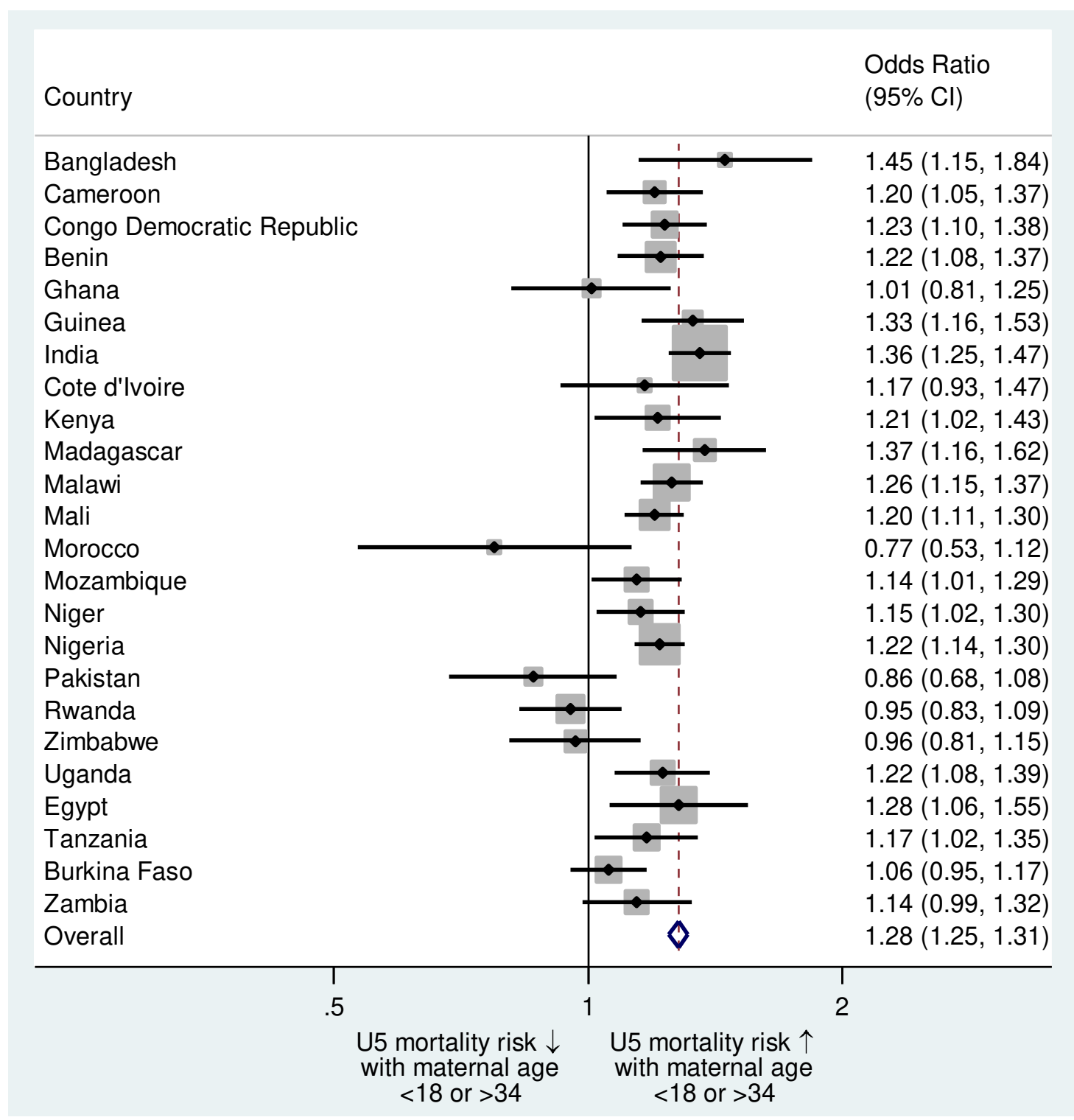


Figure 3: Under-five mortality risks with birth interval

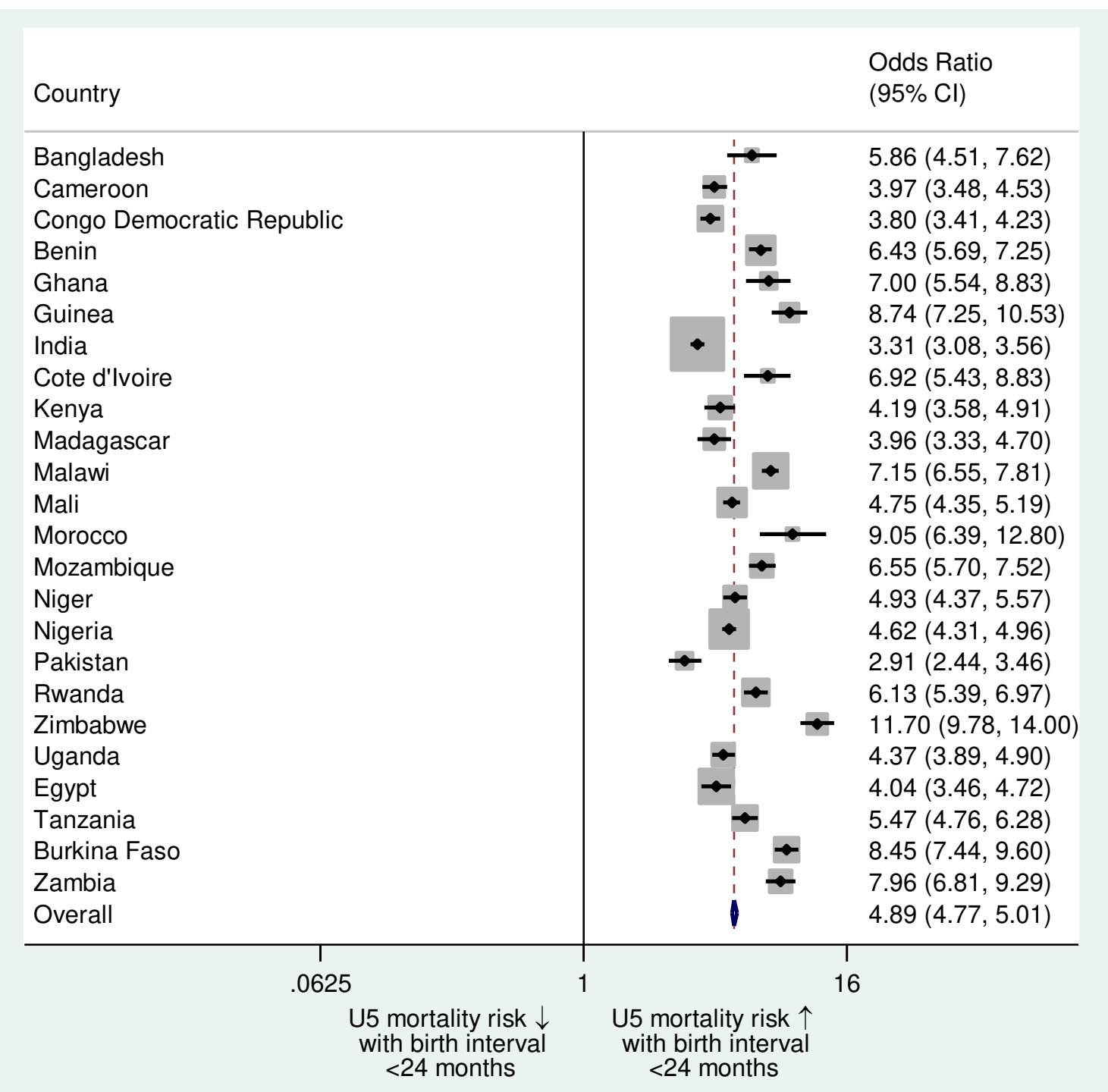


Figure 4: Under-five mortality risks with birth order

\begin{tabular}{|c|c|c|}
\hline \multicolumn{2}{|l|}{ Country } & \multirow{2}{*}{$\begin{array}{l}\text { Odds Ratio } \\
(95 \% \mathrm{Cl})\end{array}$} \\
\hline Bangladesh & 1 & \\
\hline Cameroon & -1 & $0.90(0.80,1.01)$ \\
\hline Congo Democratic Republic & $\rightarrow$ & $1.04(0.94,1.15)$ \\
\hline Benin & & $1.07(0.97,1.19)$ \\
\hline Ghana & 16 & $1.06(0.87,1.28)$ \\
\hline Guinea & $\frac{1}{1}$ & $0.94(0.83,1.07)$ \\
\hline India & & $1.13(1.06,1.21)$ \\
\hline Cote d'Ivoire & & $1.08(0.88,1.32)$ \\
\hline Kenya & 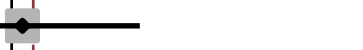 & $1.01(0.87,1.18)$ \\
\hline Madagascar & $\rightarrow$ & $1.32(1.13,1.54)$ \\
\hline Malawi & i & $0.81(0.75,0.87)$ \\
\hline Mali & $i$ & $0.84(0.78,0.90)$ \\
\hline Morocco & & $0.90(0.65,1.25)$ \\
\hline Mozambique & $\begin{array}{l}1 \\
1\end{array}$ & $0.77(0.69,0.86)$ \\
\hline Niger & +1 & $0.94(0.85,1.05)$ \\
\hline Nigeria & 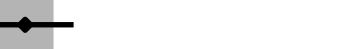 & $1.02(0.96,1.08)$ \\
\hline Pakistan & 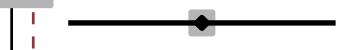 & $1.27(1.08,1.51)$ \\
\hline Rwanda & 1 & $0.83(0.73,0.93)$ \\
\hline Zimbabwe & 1 & $0.95(0.81,1.11)$ \\
\hline Uganda & 1 & $0.89(0.79,0.99)$ \\
\hline Egypt & & $1.15(0.98,1.35)$ \\
\hline Tanzania & $\mid \begin{array}{l}1 \\
1 \\
1\end{array}$ & $0.87(0.77,0.99)$ \\
\hline Burkina Faso & $t$ & $0.93(0.85,1.01)$ \\
\hline Zambia & $\begin{array}{l}1 \\
1 \\
1\end{array}$ & $0.80(0.70,0.91)$ \\
\hline Overall & 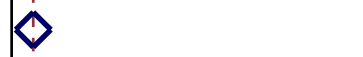 & $1.03(1.01,1.05)$ \\
\hline 1 & 1 & \\
\hline .6666667 & $\begin{array}{ll}1 & 1.5\end{array}$ & \\
\hline $\begin{array}{c}\text { U5 mortality risk } \downarrow \\
\text { with birth order } \\
>3\end{array}$ & $\begin{array}{c}\text { U5 mortality risk } \uparrow \\
\text { with birth order } \\
>3\end{array}$ & \\
\hline
\end{tabular}




\section{List of tables}

Table 1: List of recoded variables

\begin{tabular}{|c|c|c|c|}
\hline Variables & & & Categories \\
\hline Outcome variables & & & \\
\hline Under-five child mortality & & $\begin{array}{l}\text { If a child alive } \\
\text { If a child dead }\end{array}$ & Ref \\
\hline Exposure variables & & & \\
\hline $\begin{array}{l}\text { Bio-demographic risk } \\
\text { factors }\end{array}$ & Mother's age at birth & $\begin{array}{l}>=18 \text { years } \\
<18 \text { years }\end{array}$ & Ref \\
\hline & Mother's age at birth & $\begin{array}{l}<34 \text { years } \\
>=34 \text { years }\end{array}$ & Ref \\
\hline & Birth interval & $\begin{array}{l}>=24 \text { months } \\
<24 \text { months }\end{array}$ & Ref \\
\hline & Birth order & $\begin{array}{l}1-3 \\
>3\end{array}$ & Ref \\
\hline Potential confounding va & iables & & \\
\hline Birth control & Mothers of breastfeeding & $\begin{array}{l}\text { Never breastfeed } \\
\text { Ever breastfeed }\end{array}$ & Ref \\
\hline Socioeconomic controls & Women's working status & $\begin{array}{l}\text { Not currently } \\
\text { working } \\
\text { Working }\end{array}$ & Ref \\
\hline & Mother's empowerment & $\begin{array}{l}\text { Not empowered } \\
\text { Empowered }\end{array}$ & Ref \\
\hline & Mothers education & $\begin{array}{l}\text { No education } \\
\text { Primary } \\
\text { Secondary } \\
\text { Higher }\end{array}$ & Ref \\
\hline & Household wealth quintile & $\begin{array}{l}\text { Poorest } \\
\text { Poorer } \\
\text { Middle } \\
\text { Richer } \\
\text { Richest }\end{array}$ & Ref \\
\hline Demographic controls & Residential status & $\begin{array}{l}\text { Rural } \\
\text { Urban }\end{array}$ & Ref \\
\hline & The size of a child at birth & $\begin{array}{l}\text { Small } \\
\text { Average } \\
\text { Large }\end{array}$ & Ref \\
\hline
\end{tabular}


Table 2: High-risk fertility behaviours characteristic of the countries included in the study

\begin{tabular}{|c|c|c|c|c|c|c|c|c|}
\hline \multirow[b]{2}{*}{ Country } & \multicolumn{3}{|r|}{ Mortality } & \multicolumn{3}{|c|}{ Mother's age } & \multirow{2}{*}{$\begin{array}{c}\text { Interval } \\
<24\end{array}$} & \multirow{2}{*}{$\begin{array}{c}\text { Order } \\
>3\end{array}$} \\
\hline & Year & $\mathrm{N}$ & Under 5 & $<18$ & $>34$ & $<18 \mid>34$ & & \\
\hline Bangladesh & 1994 & 3870 & 79 & 14.8 & 8 & 21 & 4 & 35.3 \\
\hline Bangladesh & 1997 & 6127 & 86 & 19.5 & 6.9 & 24.9 & 8.2 & 33.2 \\
\hline Bangladesh & 2000 & 6825 & 69 & 19 & 7.3 & 24.8 & 7.9 & 28.3 \\
\hline Bangladesh & 2004 & 6873 & 67 & 18.6 & 7 & 24.3 & 7.8 & 27.4 \\
\hline Bangladesh & 2007 & 5975 & 51 & 17.9 & 6.5 & 23.2 & 6.6 & 23.4 \\
\hline Bangladesh & 2011 & 8634 & 42 & 16 & 5.6 & 20.4 & 5.1 & 18.1 \\
\hline Bangladesh & 2014 & 7977 & 38 & 16.4 & 4.9 & 20.1 & 4.5 & 15 \\
\hline Benin & 1996 & 2753 & 72 & 4.7 & 19.9 & 21.6 & 3.3 & 47.8 \\
\hline Benin & 2001 & 5008 & 100 & 5.8 & 17.5 & 20.1 & 7 & 45.3 \\
\hline Benin & 2006 & 15033 & 75 & 5 & 15.4 & 17.6 & 6.9 & 44.3 \\
\hline Benin & 2011 & 12545 & 46 & 4.5 & 15.4 & 17.1 & 7.6 & 39.8 \\
\hline Burkina Faso & 1993 & 6140 & 121 & 6.2 & 18 & 21.6 & 7.3 & 51.6 \\
\hline Burkina Faso & 1998 & 6040 & 145 & 6.6 & 20.7 & 24.2 & 7.7 & 52.1 \\
\hline Burkina Faso & 2003 & 10534 & 122 & 5.8 & 20.7 & 23.5 & 5.6 & 48.9 \\
\hline Burkina Faso & 2010 & 14776 & 81 & 5.2 & 18.7 & 20.8 & 5.7 & 47.7 \\
\hline Cameroon & 1991 & 3354 & 83 & 11.9 & 13.6 & 23.1 & 11.2 & 49.3 \\
\hline Cameroon & 1998 & 2364 & 79 & 10.8 & 14.1 & 22.6 & 6.1 & 43.8 \\
\hline Cameroon & 2004 & 7738 & 95 & 11.1 & 13.1 & 21.9 & 10.3 & 41.9 \\
\hline Cameroon & 2011 & 11251 & 82 & 9.6 & 14 & 21 & 11.1 & 42.2 \\
\hline Congo DR & 2007 & 8689 & 100 & 6.2 & 19 & 21.9 & 14.7 & 46.6 \\
\hline Congo DR & 2013 & 17692 & 68 & 6.7 & 17.4 & 21.3 & 14.6 & 47.6 \\
\hline Cote d'Ivoire & 1994 & 3853 & 83 & 11.3 & 14.7 & 23.2 & 4.2 & 47.8 \\
\hline Cote d'Ivoire & 1998 & 2112 & 137 & 11.4 & 16.3 & 24.8 & 8.9 & 43 \\
\hline Cote d'Ivoire & 2011 & 7141 & 76 & 8.9 & 15.8 & 22 & 7.5 & 40.3 \\
\hline Egypt & 1988 & 8458 & 76 & 4.7 & 15.4 & 17.2 & 19.1 & 44.9 \\
\hline Egypt & 1992 & 8473 & 66 & 3.7 & 14.9 & 16.1 & 15.5 & 43.2 \\
\hline Egypt & 1995 & 11122 & 59 & 4.5 & 13.8 & 15.7 & 12.9 & 37.4 \\
\hline Egypt & 2000 & 10949 & 39 & 3.2 & 13.1 & 13.6 & 11.8 & 32 \\
\hline Egypt & 2005 & 13045 & 31 & 3.1 & 12 & 12.7 & 9.9 & 24.2 \\
\hline Egypt & 2008 & 10176 & 22 & 2.9 & 11.3 & 11.9 & 8.2 & 20.2 \\
\hline Egypt & 2014 & 15039 & 21 & 2.2 & 10.8 & 10.7 & 9.9 & 19 \\
\hline
\end{tabular}




\begin{tabular}{|c|c|c|c|c|c|c|c|c|}
\hline Ghana & 1988 & 3970 & 103 & 5.2 & 19.1 & 21.4 & 9.5 & 46.4 \\
\hline Ghana & 1993 & 2101 & 60 & 4.6 & 18.9 & 20.2 & 3.6 & 42.2 \\
\hline Ghana & 1998 & 3052 & 70 & 4.4 & 21.4 & 22.2 & 6.4 & 40.4 \\
\hline Ghana & 2003 & 3494 & 75 & 4 & 22.9 & 23.4 & 6.7 & 41.7 \\
\hline Ghana & 2008 & 2783 & 57 & 4.6 & 20.2 & 21.1 & 6.6 & 37 \\
\hline Ghana & 2014 & 5403 & 41 & 4.4 & 22.6 & 23.2 & 7 & 36.9 \\
\hline Guinea & 1999 & 5613 & 130 & 11.4 & 17.1 & 25.3 & 8.1 & 50.4 \\
\hline Guinea & 2005 & 6034 & 107 & 10.1 & 21.2 & 27.3 & 4.7 & 50.8 \\
\hline Guinea & 2012 & 6757 & 80 & 12.5 & 17.3 & 26.7 & 6 & 44.3 \\
\hline India & 1992 & 49258 & 76 & 9.9 & 6.7 & 15.2 & 10.2 & 30.8 \\
\hline India & 1998 & 32366 & 62 & 9.6 & 5.5 & 13.7 & 7.3 & 27.3 \\
\hline India & 2005 & 55541 & 60 & 7.7 & 5.5 & 12 & 12.4 & 26.2 \\
\hline India & 2015 & 245759 & 41 & 3.3 & 5 & 7.1 & 11.4 & 14 \\
\hline Kenya & 1989 & 6937 & 72 & 7 & 17.7 & 21.5 & 15.9 & 54.1 \\
\hline Kenya & 1993 & 5958 & 74 & 6.6 & 15.3 & 19.4 & 12.6 & 48.1 \\
\hline Kenya & 1998 & 3364 & 71 & 6.4 & 13.8 & 17.3 & 7.7 & 39.6 \\
\hline Kenya & 2003 & 5901 & 84 & 7.1 & 14.7 & 19 & 12.2 & 39.6 \\
\hline Kenya & 2008 & 5698 & 58 & 6.5 & 13.2 & 17.4 & 12 & 38.9 \\
\hline Kenya & 2014 & 18951 & 40 & 6.2 & 14.3 & 17.9 & 8.8 & 34.3 \\
\hline Madagascar & 1992 & 5544 & 114 & 8.7 & 17.1 & 23 & 16.8 & 50.6 \\
\hline Madagascar & 1997 & 3818 & 87 & 10.4 & 16.3 & 23.7 & 8.5 & 45.6 \\
\hline Madagascar & 2003 & 6177 & 67 & 9.9 & 17.4 & 24.5 & 12.4 & 42.2 \\
\hline Madagascar & 2008 & 12449 & 53 & 11.1 & 18.2 & 26.5 & 11.5 & 42.8 \\
\hline Malawi & 1992 & 4390 & 159 & 8.3 & 20.5 & 25.9 & 11 & 50.9 \\
\hline Malawi & 2000 & 11662 & 124 & 7.9 & 14.9 & 20.4 & 9.2 & 40.6 \\
\hline Malawi & 2004 & 10395 & 84 & 7.9 & 13.6 & 19.2 & 7.5 & 38.9 \\
\hline Malawi & 2010 & 18850 & 77 & 7 & 14.6 & 19.2 & 7.8 & 41.8 \\
\hline Malawi & 2016 & 16556 & 43 & 8.5 & 13.9 & 19.9 & 4.8 & 36.6 \\
\hline Mali & 1987 & 3344 & 151 & 9.1 & 18.5 & 24.7 & 13.6 & 54.2 \\
\hline Mali & 1995 & 5844 & 124 & 8.7 & 18.8 & 24.2 & 6.7 & 54.9 \\
\hline Mali & 2001 & 12793 & 149 & 9.8 & 18.4 & 25.2 & 10.7 & 53.5 \\
\hline Mali & 2006 & 13941 & 124 & 10.2 & 16.7 & 24.2 & 11.2 & 51 \\
\hline Mali & 2012 & 10069 & 67 & 9.7 & 15.5 & 22.2 & 10.6 & 47.4 \\
\hline Morocco & 1987 & 5955 & 76 & 3 & 19.9 & 20 & 16.4 & 51.9 \\
\hline Morocco & 1992 & 5080 & 61 & 2.7 & 23.9 & 22.2 & 13.6 & 51.1 \\
\hline
\end{tabular}




\begin{tabular}{|c|c|c|c|c|c|c|c|c|}
\hline Morocco & 2003 & 5860 & 37 & 2.8 & 22.5 & 21.4 & 7.8 & 31.5 \\
\hline Mozambique & 1997 & 4104 & 91 & 10.4 & 15.5 & 23.1 & 4.4 & 41.6 \\
\hline Mozambique & 2003 & 10268 & 109 & 11 & 14.8 & 23.7 & 7.8 & 43.2 \\
\hline Mozambique & 2011 & 11265 & 68 & 9.9 & 17.6 & 24.6 & 7.5 & 43.3 \\
\hline Niger & 1992 & 6955 & 200 & 10.1 & 13.7 & 21.8 & 14.8 & 56 \\
\hline Niger & 1998 & 4839 & 114 & 11.9 & 17.6 & 26.4 & 7.1 & 54.8 \\
\hline Niger & 2006 & 9557 & 112 & 10.1 & 17.1 & 24.4 & 9.8 & 55.8 \\
\hline Niger & 2012 & 12882 & 74 & 8.3 & 16.5 & 21.8 & 12 & 57.1 \\
\hline Nigeria & 1990 & 7877 & 125 & 8.4 & 15.7 & 22 & 13.7 & 50.2 \\
\hline Nigeria & 1999 & 3419 & 92 & 7.8 & 16.5 & 20.6 & 6.8 & 45.8 \\
\hline Nigeria & 2003 & 5971 & 132 & 9.2 & 16.3 & 23 & 12.5 & 47.3 \\
\hline Nigeria & 2008 & 27141 & 106 & 7.5 & 18.3 & 22.6 & 12.5 & 46.9 \\
\hline Nigeria & 2013 & 30726 & 85 & 7.2 & 18.5 & 22.3 & 11.2 & 47.5 \\
\hline Pakistan & 1991 & 6349 & 92 & 4.4 & 15.9 & 17.3 & 16.8 & 49.7 \\
\hline Pakistan & 2006 & 8951 & 81 & 3.6 & 15.6 & 16.3 & 18.5 & 44.7 \\
\hline Pakistan & 2012 & 11736 & 74 & 2.6 & 13.5 & 13.2 & 19.5 & 40.1 \\
\hline Rwanda & 1992 & 5554 & 105 & 2.2 & 23.9 & 22.4 & 10.1 & 52.9 \\
\hline Rwanda & 2000 & 7984 & 137 & 2 & 25.4 & 23.7 & 12.8 & 45.8 \\
\hline Rwanda & 2005 & 8495 & 100 & 1.4 & 24.1 & 22 & 12.9 & 47.8 \\
\hline Rwanda & 2010 & 8868 & 54 & 1.3 & 21 & 19.3 & 9.6 & 40.5 \\
\hline Rwanda & 2014 & 7762 & 35 & 1.9 & 19.8 & 18.2 & 6.8 & 32.4 \\
\hline Tanzania & 1991 & 7834 & 101 & 7 & 16.7 & 21.4 & 8.9 & 44.7 \\
\hline Tanzania & 1996 & 6673 & 99 & 6.2 & 16.9 & 20.4 & 9.2 & 45.1 \\
\hline Tanzania & 1999 & 3180 & 114 & 7.1 & 15 & 19.6 & 8 & 42 \\
\hline Tanzania & 2004 & 8394 & 80 & 7 & 14.6 & 19.2 & 8.6 & 41.2 \\
\hline Tanzania & 2010 & 7939 & 57 & 6.3 & 17.8 & 20.9 & 8.2 & 43.5 \\
\hline Tanzania & 2015 & 9618 & 48 & 6.8 & 18.9 & 22.9 & 9.4 & 40.4 \\
\hline Uganda & 1988 & 4868 & 127 & 10.4 & 14.5 & 22.6 & 15.6 & 50.4 \\
\hline Uganda & 1995 & 5836 & 90 & 10.1 & 12.7 & 20.7 & 12.7 & 46.3 \\
\hline Uganda & 2001 & 7466 & 106 & 8.7 & 13.9 & 20.1 & 15.7 & 48.6 \\
\hline Uganda & 2006 & 8162 & 86 & 6.2 & 15.9 & 19.4 & 14.5 & 53.5 \\
\hline Uganda & 2011 & 7813 & 63 & 6.7 & 16.7 & 20.2 & 14.2 & 50.5 \\
\hline Zambia & 1992 & 6040 & 133 & 9.8 & 15 & 22.4 & 9.4 & 45.8 \\
\hline Zambia & 1996 & 6883 & 141 & 8.8 & 13.5 & 20.1 & 10.8 & 43.2 \\
\hline Zambia & 2001 & 6430 & 121 & 9.9 & 14.5 & 22.1 & 7.9 & 42.3 \\
\hline
\end{tabular}




\begin{tabular}{lcccccccc} 
Zambia & 2007 & 6156 & 82 & 7 & 15.5 & 20 & 9 & 44.8 \\
Zambia & 2013 & 12970 & 52 & 8 & 17 & 21.9 & 7.8 & 44.6 \\
Zimbabwe & 1988 & 3228 & 55 & 6.1 & 16.4 & 20.3 & 8.9 & 47.7 \\
Zimbabwe & 1994 & 2298 & 58 & 6.8 & 16 & 19.8 & 3.2 & 37.7 \\
Zimbabwe & 1999 & 3451 & 76 & 7.8 & 14 & 19.5 & 4.9 & 29.2 \\
Zimbabwe & 2005 & 5075 & 64 & 7.2 & 11.4 & 16.5 & 4.5 & 25.6 \\
Zimbabwe & 2010 & 5444 & 64 & 7.5 & 11.4 & 16.6 & 4.2 & 22.4 \\
Zimbabwe & 2015 & 6138 & 53 & 6.6 & 14.5 & 18.4 & 5.3 & 28.1 \\
\hline Average & & & 83.7 & 7.7 & 15.6 & 20.7 & 9.6 & 42 \\
Min & & 21 & 1.3 & 4.9 & 7.1 & 3.2 & 14 \\
Max & & 200 & 19.5 & 25.4 & 27.3 & 19.5 & 57.1 \\
\hline
\end{tabular}

Mother's age refers to the mother's age at the time of childbirth; Interval and Order refer to the Birth Interval and Birth Order, respectively. 
Table 3: Associations between any high-risk category of fertility behaviours among women aged 15-49 years and under-five child mortality 5 years preceding the survey.

OR $95 \% \mathrm{CI}$

Any High-Risk Category

No

Yes

Ever Breastfed

Never Breastfed

Ever Breastfed

Woman's working status

Not currently working

Working

Mother's empowerment

Not empowered

Empowered

Residence

Rural

Urban

Mother's education

No Education

Primary

Secondary

Higher

Size of child at birth

Small

Average

Household wealth index

Poorest

Poorer

Middle

Richer
1

$1.771^{\text {*** }}$

1

$0.0522^{* * *}$

1

$1.114^{* * * *}$

1

$0.944^{* * *}$

1

$0.905^{* * *}$

1

$0.958^{*}$

$0.768^{* * *}$

$0.531^{* * *}$

1

$0.715^{* * *}$

$0.707^{\text {*** }}$

1

0.978

$0.906^{* * *}$

$0.860^{\text {**** }}$
[0.870,0.942]

[1,1]

[1.722,1.821]

[1,1]

[0.0502,0.0544]

[1,1]

[1.080,1.149]

[1,1]

[0.917,0.970]

$[1,1]$

$[1,1]$

[0.927,0.990]

[0.734,0.804]

[0.473,0.595]

$[1,1]$

[0.692,0.740]

$[0.681,0.733]$

$[1,1]$

[0.944,1.013]

[0.873,0.941]

[0.825,0.897] 


\begin{tabular}{|c|c|c|}
\hline Richest & $0.698^{* * *}$ & {$[0.659,0.740]$} \\
\hline Bangladesh & 1 & {$[1,1]$} \\
\hline Cameroon & $2.416^{* * *}$ & {$[2.078,2.810]$} \\
\hline Congo Democratic Republic & $2.656^{* * *}$ & {$[2.225,3.170]$} \\
\hline Benin & 0.986 & {$[0.841,1.156]$} \\
\hline Ghana & $1.732^{* * *}$ & {$[1.467,2.044]$} \\
\hline Guinea & $3.086^{* * *}$ & {$[2.625,3.628]$} \\
\hline India & $2.071^{* * *}$ & {$[1.799,2.386]$} \\
\hline Cote d'Ivoire & $1.950^{* * * *}$ & {$[1.579,2.410]$} \\
\hline Kenya & $1.881^{* * *}$ & {$[1.607,2.201]$} \\
\hline Madagascar & $1.643^{* * * *}$ & {$[1.390,1.943]$} \\
\hline Malawi & $2.337^{* * *}$ & {$[2.078,2.629]$} \\
\hline Mali & $1.757^{* * *}$ & {$[1.496,2.064]$} \\
\hline Morocco & $0.671^{* * * *}$ & {$[0.547,0.825]$} \\
\hline Mozambique & $2.641^{* * * *}$ & {$[2.267,3.077]$} \\
\hline Niger & $2.290^{* * * *}$ & {$[1.938,2.705]$} \\
\hline Nigeria & $3.845^{* * *}$ & {$[3.321,4.452]$} \\
\hline Pakistan & $2.302^{* * *}$ & {$[1.902,2.786]$} \\
\hline Rwanda & $1.696^{* * *}$ & {$[1.495,1.926]$} \\
\hline Zimbabwe & $3.449^{* * *}$ & {$[2.964,4.014]$} \\
\hline Uganda & $1.495^{* * * *}$ & {$[1.270,1.760]$} \\
\hline Egypt & $0.532^{* * * *}$ & {$[0.466,0.607]$} \\
\hline Tanzania & $2.141^{* * *}$ & {$[1.851,2.477]$} \\
\hline Burkina Faso & $3.043^{* * *}$ & [2.646,3.499] \\
\hline Zambia & $1.452^{* * *}$ & {$[1.238,1.703]$} \\
\hline 1998 & 1 & {$[1,1]$} \\
\hline 1999 & 0.983 & {$[0.816,1.185]$} \\
\hline 2000 & $2.530^{* * *}$ & {$[2.263,2.828]$} \\
\hline 2001 & $3.100^{* * * *}$ & {$[2.704,3.553]$} \\
\hline 2003 & $1.487^{* * * *}$ & {$[1.317,1.679]$} \\
\hline 2004 & $1.299^{* * * *}$ & {$[1.148,1.470]$} \\
\hline
\end{tabular}




\begin{tabular}{lll}
2005 & $0.876^{* * *}$ & {$[0.811,0.945]$} \\
2006 & $1.900^{* * *}$ & {$[1.655,2.181]$} \\
2007 & $1.467^{* * *}$ & {$[1.236,1.742]$} \\
2008 & 0.949 & {$[0.834,1.080]$} \\
2010 & 0.968 & {$[0.867,1.080]$} \\
2011 & 1.001 & {$[0.876,1.143]$} \\
2012 & 0.967 & {$[0.844,1.109]$} \\
2013 & $0.737^{* * *}$ & {$[0.644,0.842]$} \\
2014 & 0.884 & {$[0.774,1.009]$} \\
2015 & $0.512^{* * *}$ & {$[0.467,0.561]$} \\
2016 & $0.601^{* * *}$ & {$[0.510,0.708]$} \\
\hline Log-Likelihood & -134903.7 & \\
$\chi^{2}$ & 28274.6 & \\
P & 0.000 & \\
\hline
\end{tabular}

Exponentiated coefficients; $95 \%$ confidence intervals in brackets

${ }^{*} p<0.05,{ }^{* *} p<0.01,{ }^{* * *} p<0.001$ 
Table 4: Associations between high-risk fertility behaviours among women aged 15-49 years and under-five child mortality 5 years preceding the survey.

\begin{tabular}{|c|c|c|c|c|c|c|c|c|}
\hline & \multicolumn{2}{|c|}{ Model (1) } & \multicolumn{2}{|c|}{ Model (2) } & \multicolumn{2}{|c|}{ Model (3) } & \multicolumn{2}{|c|}{ Model (4) } \\
\hline & OR & $95 \% \mathrm{CI}$ & OR & $95 \% \mathrm{CI}$ & OR & $95 \% \mathrm{CI}$ & OR & $95 \% \mathrm{CI}$ \\
\hline \multicolumn{9}{|l|}{ Mother's age at birth } \\
\hline$>=18$ & 1 & {$[1,1]$} & & & & & & \\
\hline$<18$ & $1.488^{* * *}$ & {$[1.426,1.553]$} & & & & & & \\
\hline $\begin{array}{l}\text { Mother's age at birth } \\
\text { (years) }\end{array}$ & & & & & & & & \\
\hline$<34$ & & & 1 & {$[1,1]$} & & & & \\
\hline$>=34$ & & & 0.972 & {$[0.939,1.006]$} & & & & \\
\hline \multicolumn{9}{|l|}{ Birth interval (months) } \\
\hline$>=24$ & & & & & 1 & {$[1,1]$} & & \\
\hline$<24$ & & & & & $4.995^{* * *}$ & {$[4.842,5.152]$} & & \\
\hline \multicolumn{9}{|l|}{ Birth order of the child } \\
\hline $1-3$ & & & & & & & 1 & {$[1,1]$} \\
\hline$>3$ & & & & & & & $0.957^{* *}$ & {$[0.932,0.983]$} \\
\hline \multicolumn{9}{|l|}{ Ever breastfed } \\
\hline Never breastfed & 1 & {$[1,1]$} & 1 & {$[1,1]$} & 1 & {$[1,1]$} & 1 & {$[1,1]$} \\
\hline Ever breastfed & $0.0512^{* * *}$ & {$[0.0492,0.0533]$} & $0.0509^{* * *}$ & {$[0.0489,0.0529]$} & $0.0566^{* * *}$ & {$[0.0542,0.0591]$} & $0.0509^{* * *}$ & {$[0.0489,0.0530]$} \\
\hline $\begin{array}{l}\text { Woman's working } \\
\text { status }\end{array}$ & \multicolumn{7}{|c|}{ status } & \\
\hline Not currently working & 1 & {$[1,1]$} & 1 & {$[1,1]$} & 1 & {$[1,1]$} & 1 & {$[1,1]$} \\
\hline Working & $1.161^{* * *}$ & {$[1.126,1.197]$} & $1.147^{* * *}$ & {$[1.112,1.183]$} & $1.172^{* * *}$ & {$[1.136,1.210]$} & $1.150^{* * *}$ & {$[1.115,1.186]$} \\
\hline \multicolumn{9}{|l|}{ Mother's } \\
\hline \multicolumn{9}{|l|}{ empowerment } \\
\hline Not empowered & 1 & {$[1,1]$} & 1 & {$[1,1]$} & 1 & {$[1,1]$} & 1 & {$[1,1]$} \\
\hline Empowered & $0.964^{*}$ & {$[0.937,0.991]$} & $0.954^{* *}$ & {$[0.927,0.981]$} & $0.964^{*}$ & {$[0.937,0.992]$} & $0.955^{* *}$ & {$[0.928,0.982]$} \\
\hline \multicolumn{9}{|l|}{ Residence } \\
\hline Rural & 1 & {$[1,1]$} & 1 & {$[1,1]$} & 1 & {$[1,1]$} & 1 & {$[1,1]$} \\
\hline Urban & $0.900^{* * *}$ & {$[0.865,0.937]$} & $0.899^{* * * *}$ & {$[0.864,0.936]$} & $0.902^{* * *}$ & {$[0.866,0.940]$} & $0.898^{* * *}$ & {$[0.863,0.935]$} \\
\hline \multicolumn{9}{|l|}{ Mother's education } \\
\hline No Education & 1 & {$[1,1]$} & 1 & {$[1,1]$} & 1 & {$[1,1]$} & 1 & {$[1,1]$} \\
\hline Primary & $0.904^{* * *}$ & {$[0.875,0.934]$} & $0.910^{* * * *}$ & {$[0.881,0.941]$} & $0.905^{* * *}$ & {$[0.875,0.936]$} & $0.907^{* * *}$ & {$[0.878,0.938]$} \\
\hline Secondary & $0.672^{* * *}$ & {$[0.642,0.703]$} & $0.671^{* * *}$ & {$[0.641,0.702]$} & $0.676^{* * *}$ & {$[0.645,0.708]$} & $0.665^{* * *}$ & {$[0.635,0.696]$} \\
\hline Higher & $0.452^{* * *}$ & {$[0.403,0.506]$} & $0.443^{* * *}$ & {$[0.395,0.496]$} & $0.445^{* * *}$ & {$[0.394,0.502]$} & $0.437^{* * *}$ & {$[0.390,0.490]$} \\
\hline \multicolumn{9}{|l|}{ Size of child at birth } \\
\hline Small & 1 & {$[1,1]$} & 1 & {$[1,1]$} & 1 & {$[1,1]$} & 1 & {$[1,1]$} \\
\hline Average & $0.722^{* * *}$ & {$[0.698,0.747]$} & $0.716^{* * *}$ & {$[0.692,0.740]$} & $0.721^{* * * *}$ & {$[0.697,0.746]$} & $0.717^{* * *}$ & {$[0.693,0.741]$} \\
\hline
\end{tabular}




\begin{tabular}{|c|c|c|c|c|c|c|c|c|}
\hline Large & $0.718^{* * *}$ & {$[0.692,0.744]$} & $0.710^{* * * *}$ & {$[0.685,0.737]$} & $0.722^{* * *}$ & {$[0.695,0.750]$} & $0.711^{* * *}$ & {$[0.686,0.738]$} \\
\hline \multicolumn{9}{|l|}{ Household wealth } \\
\hline \multicolumn{9}{|l|}{ index } \\
\hline Poorest & 1 & {$[1,1]$} & 1 & {$[1,1]$} & 1 & {$[1,1]$} & 1 & {$[1,1]$} \\
\hline Poorer & 0.970 & {$[0.937,1.005]$} & 0.971 & {$[0.938,1.006]$} & 0.976 & {$[0.941,1.011]$} & 0.971 & {$[0.937,1.005]$} \\
\hline Middle & $0.898^{* * *}$ & {$[0.866,0.932]$} & $0.896^{* * *}$ & {$[0.864,0.930]$} & $0.901^{* * * *}$ & {$[0.867,0.936]$} & $0.895^{* * *}$ & {$[0.863,0.929]$} \\
\hline Richer & $0.851^{* * *}$ & {$[0.816,0.887]$} & $0.845^{* * *}$ & {$[0.810,0.881]$} & $0.850^{* * * *}$ & {$[0.814,0.887]$} & $0.844^{* * *}$ & {$[0.809,0.880]$} \\
\hline Richest & $0.679^{* * *}$ & {$[0.641,0.719]$} & $0.671^{* * *}$ & {$[0.634,0.711]$} & $0.682^{* * *}$ & {$[0.643,0.723]$} & $0.669^{* * *}$ & {$[0.632,0.709]$} \\
\hline Country fixed effects & Yes & & Yes & & Yes & & Yes & \\
\hline Time-fixed effects & Yes & & Yes & & Yes & & Yes & \\
\hline Log-Likelihood & -135935.6 & & -136160.0 & & -129219.6 & & -136154.3 & \\
\hline$\chi^{2}$ & 27299.2 & & 27110.7 & & 31291.5 & & 27114.3 & \\
\hline$P$ & 0 & & 0 & & 0 & & 0 & \\
\hline
\end{tabular}

Exponentiated coefficients; $95 \%$ confidence intervals in brackets

${ }^{*} p<0.05,{ }^{* *} p<0.01,{ }^{* * *} p<0.001$ 
Table 5: Associations between multiple high-risk category of fertility behaviours among women aged 15-49 years and under-five child mortality 5 years preceding the survey

\begin{tabular}{|c|c|c|}
\hline & Adj OR & $95 \% \mathrm{CI}$ \\
\hline \multicolumn{3}{|c|}{ Age at birth $<18$ years and birth interval $<24$ months } \\
\hline No (Ref) & 1 & {$[1,1]$} \\
\hline Yes & $4.663^{* * *}$ & {$[4.300,5.057]$} \\
\hline \multicolumn{3}{|c|}{ Age at birth $<18$ years and birth order $>3$} \\
\hline No (Ref) & 1 & {$[1,1]$} \\
\hline Yes & 0.818 & {$[0.300,2.227]$} \\
\hline \multicolumn{3}{|c|}{ Age at birth $<18$ years and birth interval $<24$ months and birth order $>3$} \\
\hline No (Ref) & 1 & {$[1,1]$} \\
\hline Yes & 2.100 & {$[0.322,13.68]$} \\
\hline \multicolumn{3}{|c|}{ Age at birth $>34$ years and birth interval $<24$ months } \\
\hline No (Ref) & 1 & {$[1,1]$} \\
\hline Yes & $4.324^{* * *}$ & {$[3.978,4.701]$} \\
\hline \multicolumn{3}{|c|}{ Age at birth $>34$ years and birth order $>3$} \\
\hline No (Ref) & 1 & {$[1,1]$} \\
\hline Yes & 0.985 & {$[0.951,1.020]$} \\
\hline \multicolumn{3}{|c|}{ Age at birth $>34$ years and birth interval $<24$ months and birth order $>3$} \\
\hline No (Ref) & 1 & {$[1,1]$} \\
\hline Yes & $4.537^{* * *}$ & {$[4.162,4.945]$} \\
\hline \multicolumn{3}{|c|}{ Birth interval $<24$ months and birth order $>3$} \\
\hline No (Ref) & 1 & {$[1,1]$} \\
\hline Yes & $4.568^{* * *}$ & {$[4.362,4.783]$} \\
\hline Country fixed effects & Yes & Yes \\
\hline Time-fixed effects & Yes & Yes \\
\hline \multicolumn{3}{|c|}{ Exponentiated coefficients; $95 \%$ confidence intervals in brackets } \\
\hline${ }^{*} p<0.05,{ }^{* *} p<0.01,{ }^{*}$ & & \\
\hline
\end{tabular}


Figures

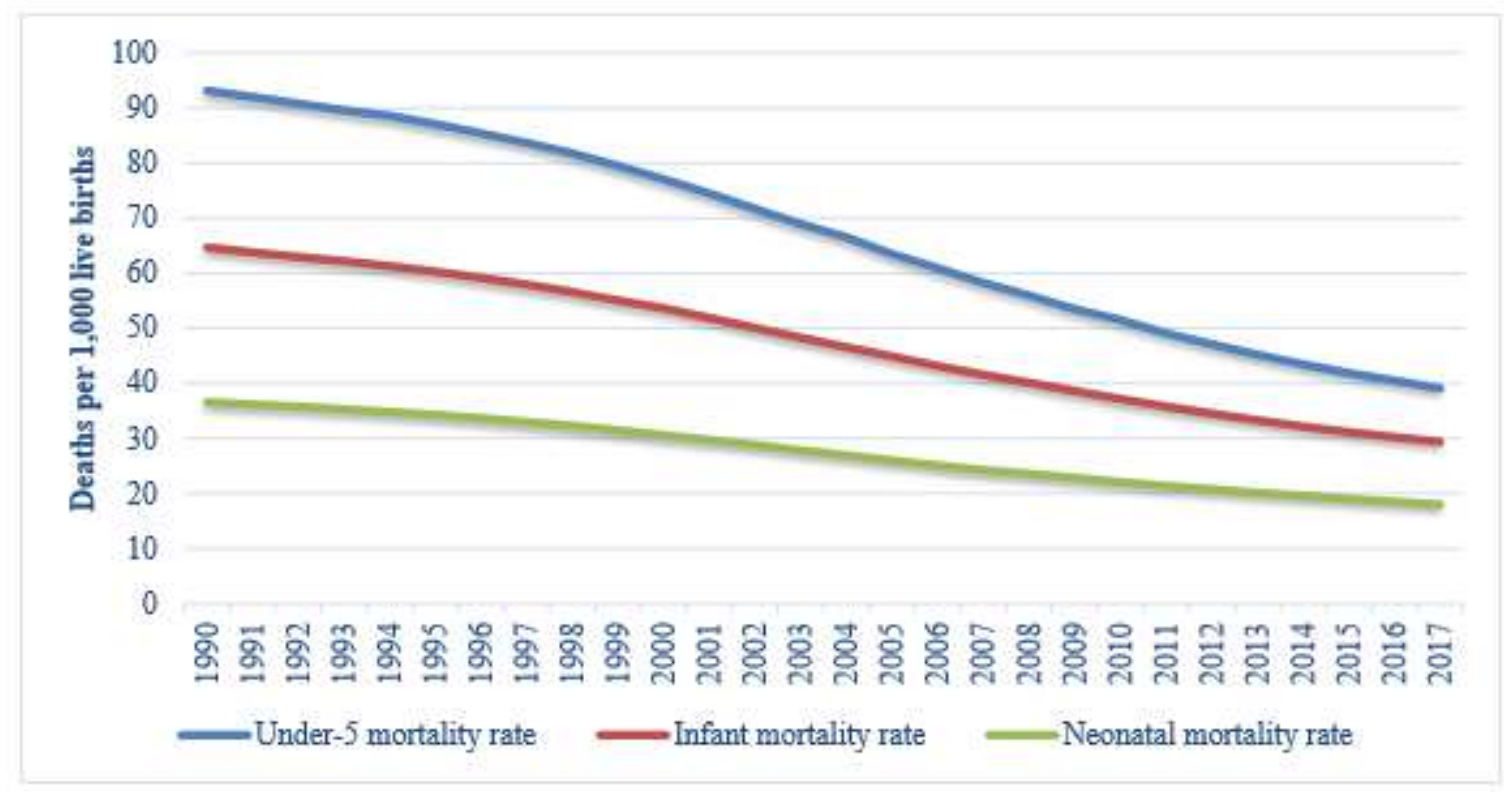

Source: United Nations Inter-Agency Group for Child Mortality Estimation (UNIGME) 2018

\section{Figure 1}

Global under-five, neonatal, infant mortality rates (1990-2017) 


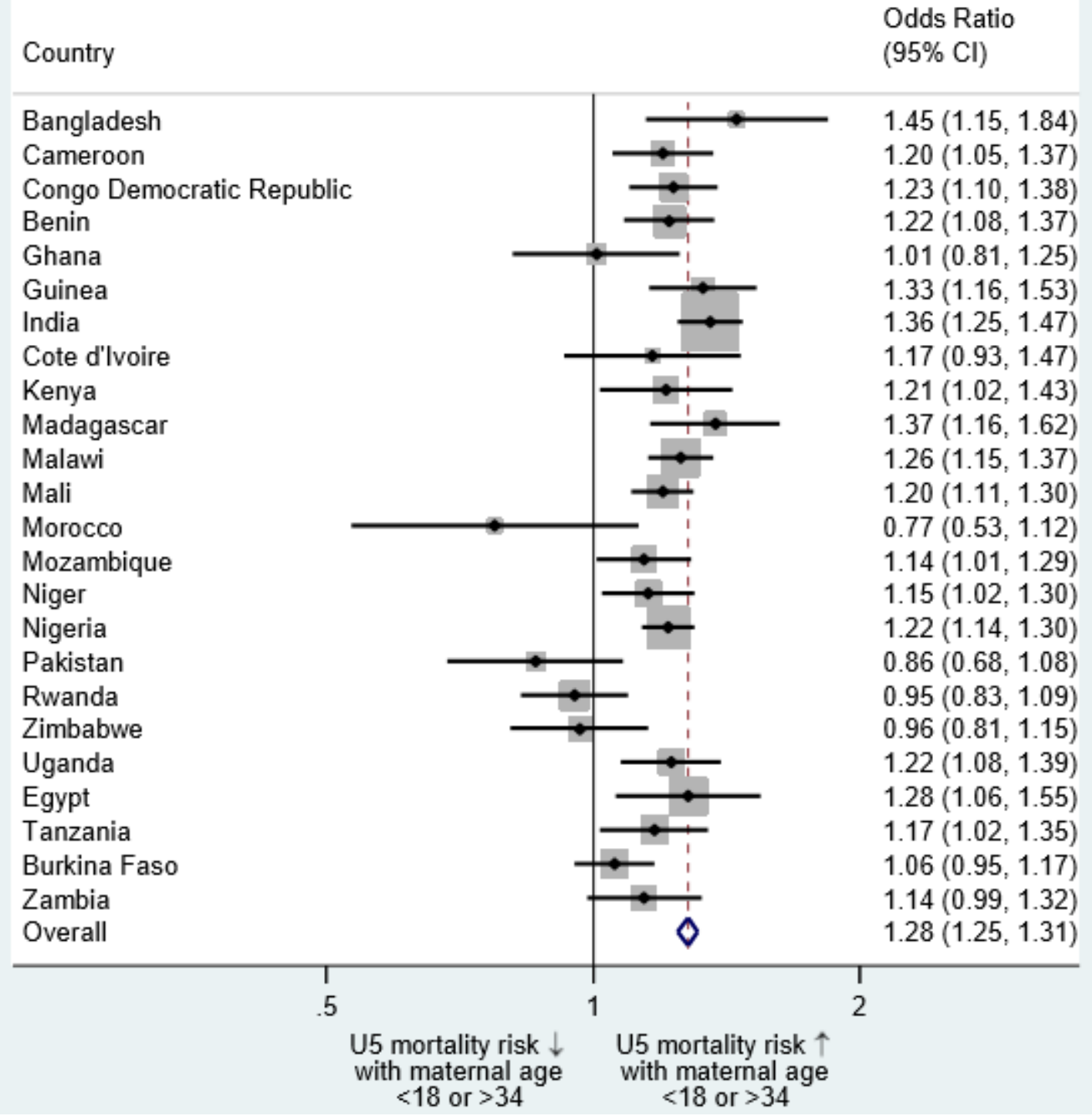

Figure 2

Under-five mortality risks with mother's age 


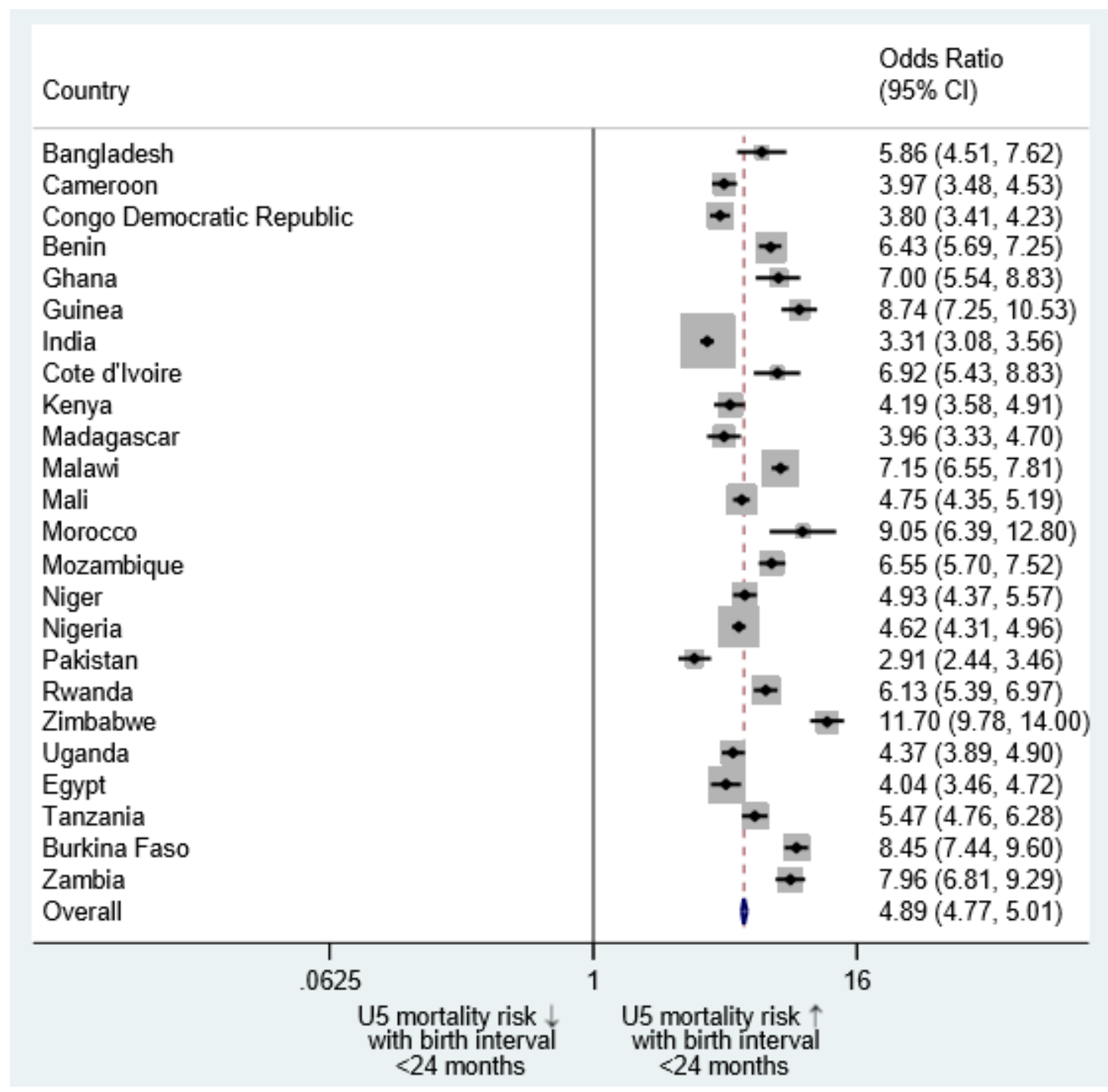

\section{Figure 3}

Under-five mortality risks with birth interval 


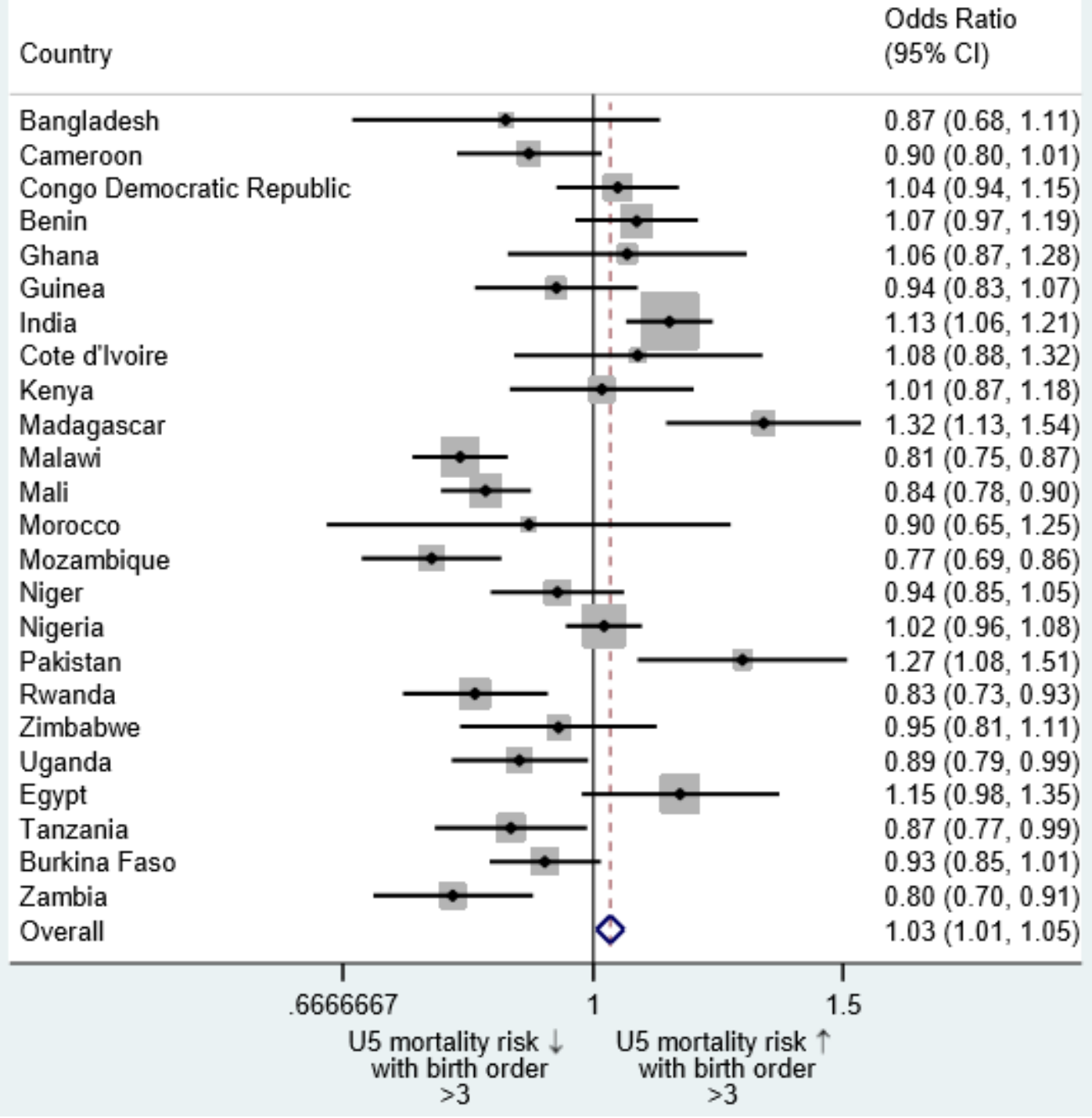

\section{Figure 4}

Under-five mortality risks with birth order 